\title{
La dimensión regional de la emigración mexicana hacia Estados Unidos
}

\author{
Daniel Delaunay*
}

La emigración mexicana hacia Estados Unidos tiene más de un siglo de historia, pero es muy reciente que estadísticas serias documenten su distribución geográfica. Tanto esta nueva información, como la elaboración de un Sistema de Información Geográfica sobre México y el desarrollo reciente del análisis multinivel, han permitido examinar el contexto regional de la emigración mexicana hacia Estados Unidos. ¿Corresponde a la distribución geográfica de la pobreza, del subempleo, a la de la productividad de los trabajadores o de la inversión productiva? $O$, simplemente, ¿depende de la proximidad a la frontera norte? ¿Es comparable la lógica espacial de la migración internacional a la de la movilidad interna?

Más allá de las enseñanzas que puedan aportar las respuestas a estas interrogantes, el presente estudio utiliza dos nuevas herramientas de análisis contextual y examina su utilidad para el estudio de la migración internacional: en primer. lugar, los Sistemas de Información Geográfica que proporcionan una medición de los factores físicos (aridez, aislamiento, uso del suelo, degradación del medio ambiente...) junto con las estadísticas socioeconómicas, la organización y la reproducción de la familia... Pero el contexto regional no influye directamente en la decisión de emigrar, y parece más bien manifestarse mediante parámetros individuales o familiares, ya que esta decisión es antes que nada personal o familiar. Se coteja la información de los distintos niveles de observación con el fin de discernir lo que atañe al individuo, a la familia o a la región en la migración internacional.

\section{Introducción}

Si bien migrar es una decisión individual, implica la elección de lugares compartidos: en efecto, el emigrante decide cambiar el contexto regional de su actividad económica o de su vida social. De modo que resulta legítimo buscar entre las características regionales algunas fuerzas de expulsión o de atracción que modulen los flujos migratorios; he aquí una preocupación frecuente en el estudio de las migra-

* Demoeconomista del ORSTOM. El presente estudio, la información utilizada y la elaboración de las herramientas empleadas, son el resultado de un acuerdo de cooperación científica entre El Colegio de la Frontera Norte en Tijuana (Colef) y L'Institut Français de Recherche en Coopération pour le Développement (ORSTOM). La traducción es de Adrien Pellaumail. La revisión la realizó Carlos Echarri. 
ciones internas ya que se puede pensar que éstas reflejan la desigual distribución geográfica de la economía del país. Para la migración internacional, en cambio, el poder de atracción de la nación receptora tiende a ocultar la fuerza de expulsión de las regiones de origen. Con todo, las recientes estadísticas lo demuestran: el éxodo hacia Estados Unidos no se distribuye de manera aleatoria en el territorio mexicano, sino todo lo contrario. Y rara vez se plantea la cuestión de la distribución geográfica interna de la migración internacional, para averiguar si desde el lugar de origen algunas regiones favorecen o disuaden la migración. La primera parte de este trabajo se dedicará a determinar si la migración internacional presenta una lógica regional. En caso afirmativo, ¿puede ser explicada?, ¿es similar a la de la migración interna?, ¿corresponde a la disposición geográfica de ciertas variables naturales o socioeconómicas? Esta primera aproximación exploratoria - sin hipótesis preliminar- se llevará a cabo con base en estadísticas regionales, o sea indicadores agregados tanto de la migración como de los contextos socioeconómicos y naturales.

Pero la evaluación de los lugares de origen y de destino contribuye tan sólo en parte a la decisión del emigrante, la cual obedece también a motivaciones individuales o familiares y hasta comunitarias... Es incluso probable que la distribución geográfica de la emigración se explique en parte por la configuración espacial de dichos factores individuales o familiares. De modo que para averiguarlo se deben combinar estos diversos niveles de observación en un mismo análisis, admitiendo que todos contribuyen conjuntamente a su explicación. Pero ¿cómo disociar estos tres efectos con las estadísticas disponibles? En la segunda parte de este artículo se abordará la cuestión de manera pragmática, es decir sin hipótesis teórica previa, con las estadísticas disponibles - pero sin dejar de subrayar sus limitaciones-, experimentando dos nuevas herramientas de análisis contextual que son los Sistemas de Información Geográfica (que aportan la información espacial) y los modelos jerárquicos o multiniveles (que analizan la información jerarquizada proveniente de distintos niveles de información).

Si bien estas cuestiones casi no se suelen plantear, es aún menos frecuente utilizar estas herramientas en el análisis demográfico, particularmente el de la migración, lo que constituye la primera originalidad de este estudio.

Cabe recordar que los Sistemas de Información Geográfica son las herramientas del análisis relacional de una información localizada; 
estos bancos de datos fueron diseñados con el fin de capturar, actualizar, cuestionar, y analizar una información georreferenciada. Sobre todo, a través de la referencia espacial permiten relacionar entre sí distintos niveles de información que de otra manera quedarían aislados en distintos cortes espaciales. De modo que para este estudio se cruzará la información proveniente de los censos socioeconómicos con la de los inventarios naturales. La información regional utilizada para probar los eventuales efectos del medio ambiente será extraída del SIGEF, ${ }^{1}$ sistema de información elaborado en El Colegio de la Frontera Norte, Tijuana (Colef) para México.

El análisis multinivel es una de las denominaciones para el conjunto de técnicas estadísticas que permiten medir los efectos contextuales, superando el problema de la elección de las unidades de observación (que suelen yuxtaponerse) y de los sesgos introducidos por las observaciones individuales. Considera que los individuos pertenecen a grupos (escuelas, empresas, comunidades, regiones); de esta pertenencia se deriva una mayor similitud que conviene medir y que se habrá de tomar en cuenta para la estimación de los parámetros estadísticos.

En el anexo se encuentra una sección metodológica que justifica la elección de la metodología.

La distribución geográfica de la emigración mexicana hacia Estados Unidos

\section{Las estadísticas utilizadas}

No es sino hasta mediados de los años noventa cuando la geografía mexicana del éxodo hacia Estados Unidos se empezó a medir con una precisión municipal. Sin embargo, a la hora de elegir entre distintas medidas, pueden aparecer ciertas discordancias, por ejemplo entre las estadísticas de la movilidad hacia el extranijero (Emif) ${ }^{2}$ y las de los emigrantes que viven en Estados Unidos o que han regresado a México (Enadid). ${ }^{3}$ Ambas utilizan el municipio como referencia

\footnotetext{
${ }^{1}$ Sistema de Información Geográfica y Estadística de la Frontera Norte (SIGEF) cuyos coordinadores son Daniel Delaunay para el ORSTOM y Jorge Santibáñez para el Colef. "Savane", el programa de cómputo central en el SIGEF ha sido elaborado con base en una plataforma SUN por Marc Souris y Michel Lepage.

2 Encuesta sobre Migración en la Frontera Norte de México (Colef et al., 1994).

${ }^{3}$ Encuesta Nacional de la Dinámica Demográfica (INEGI, 1994).
} 
espacial, pero sin contar con la representatividad estadística necesaria para este nivel regional de observación muy precisa. ${ }^{4}$ Para intentar reducir las fluctuaciones aleatorias de nuestras estimaciones, se usó una división intermedia del espacio, con 198 "regiones de programación" 5 elaboradas por la Secretaría de Programación y Presupuesto. Se trata de una reagrupación de municipios colindantes considerados como similares en el nivel económico o natural, con el fin de obtener regiones más homogéneas que se mantengan en el marco de los límites administrativos, particularmente los del estado.

La Enadid, en la cual finalmente nos basaremos, ha realizado un esfuerzo innovador en cuanto a la estimación de la migración tanto interna -ya que incluye la medición de la movilidad entre los municipios de un mismo estado-, como internacional. Es la única de su tipo en haber sido diseñada con el fin de obtener una buena representatividad espacial. Lo malo de esta encuesta, como de todas las que se realizan en el lugar de origen de los emigrantes, es que registra los regresos con mayor facilidad que las ausencias. ${ }^{6}$ Trata de identificar a los emigrantes que se encuentran en Estados Unidos por medio de preguntas formuladas a los miembros de los hogares que se quedaron en México, pero estas estadísticas sólo están disponibles para el estado de origen del emigrante y no para el municipio. En relación con esta última unidad espacial, mucho más precisa, sólo contamos con el número de personas que han emigrado a Estados Unidos para trabajar y han regresado a México; probablemente debido a exigencias de confidencialidad solamente se encuentran informaciones relativas al municipio de nacimiento. Por lo tanto, todas las estadísticas migratorias analizadas en este trabajo -ya sea del éxodo internacional o de la movilidad interna entre estados o entre los mu-

${ }^{4}$ Un fenómeno tan poco frecuente como la migración internacional sólo puede ser medido mediante un censo exhaustivo.

${ }^{5}$ Entre los 2400 municipios y los 32 estados que existen en México.

${ }^{6}$ La alternativa estadística planteada y explorada es una encuesta innovadora que mide los flujos migratorios desde la frontera, la Emif, basándose en poblaciones móviles, realizada por el Colef a cargo de Jorge Bustamante, Jorge Santibáñez y Rodolfo Corona. El cálculo se opera con base en la información recabada en unos puestos de encuesta instalados en la entrada de la región fronteriza. Ahí se selecciona una muestra aleatoria de pasajeros a quienes se aplica un filtro y un cuestionario. El presente estudio no prosiguió con esta encuesta por considerar que su representatividad espacial es menos sólida, y porque la movilidad que mide difiere notablemente de las migraciones acumuladas que hemos decidido analizar (el tiempo de la estancia tiende a prevalecer sobre la probabilidad de migrar cuando se trata de una migración internacional estrechamente vinculada con la temporalidad laboral). 
nicipios de un mismo estado-, corresponderán al lugar de nacimiento. Esta conformación de los datos nos lleva a conservar únicamente las migraciones acumuladas, tanto en el caso de los movimientos internos -puesto que el individuo interrogado reportará haber dejado su estado natal-, como en el de la migración internacional, cuando, de vuelta a México, éste declare haber trabajado en Estados Unidos. Con el fin de no tomar exclusivamente en cuenta esta migración que ya se había concluido cuando se realizó la encuesta, y como la estadística parcial de los retornos no habría podido ofrecer un panorama completo del éxodo, se han incluido a los nativos mexicanos que radican actualmente en Estados Unidos. Puesto que sólo disponemos de datos relativos a los estados, el detalle regional de los ausentes -los verdaderos emigrantes en el momento de la encuesta- es producto de una interpolación de las mediciones relativas a los estados. De modo que las estadísticas analizadas y cartografiadas se refieren tanto a los emigrantes del pasado como a los del presente, y no a migraciones; se expresan en términos absolutos (número de emigrantes) o en proporción de la población total que ha contestado a las preguntas sobre migración de la encuesta. Asimismo, para distinguir los movimientos internos de las migraciones internacionales, se definen como "migrantes internacionales" a las personas que habían trabajado en Estados Unidos, hayan nacido o no en el estado del que salieron. ${ }^{7}$

\section{La configuración espacial del éxodo}

Los siguientes mapas ilustran las configuraciones regionales que caracterizan las tres formas de la movilidad en México hasta 1992: la que se orienta hacia el extranjero, la que va de un estado a otro, y la de los movimientos intermunicipales dentro de los límites del estado -aunque estas dos últimas no sean siempre excluyentes. Casi no se hallan semejanzas entre las tres configuraciones espaciales, como lo confirman las escasas correlaciones entre los valores regionales de la magnitud relativa de cada contribución migratoria (entre 0.1 y 0.17 , algunas de ellas no significativas) a pesar de que los contextos natu-

\footnotetext{
7 Desgraciadamente hay que reconocer que alrededor de $1 \%$ de las personas que declaran no haber vivido nunca en otro estado o en el extranjero se considera a sí mismo como "trabajador internacional" (desde luego de retorno), lo que representa casi la quinta parte de los emigrantes internacionales.
} 


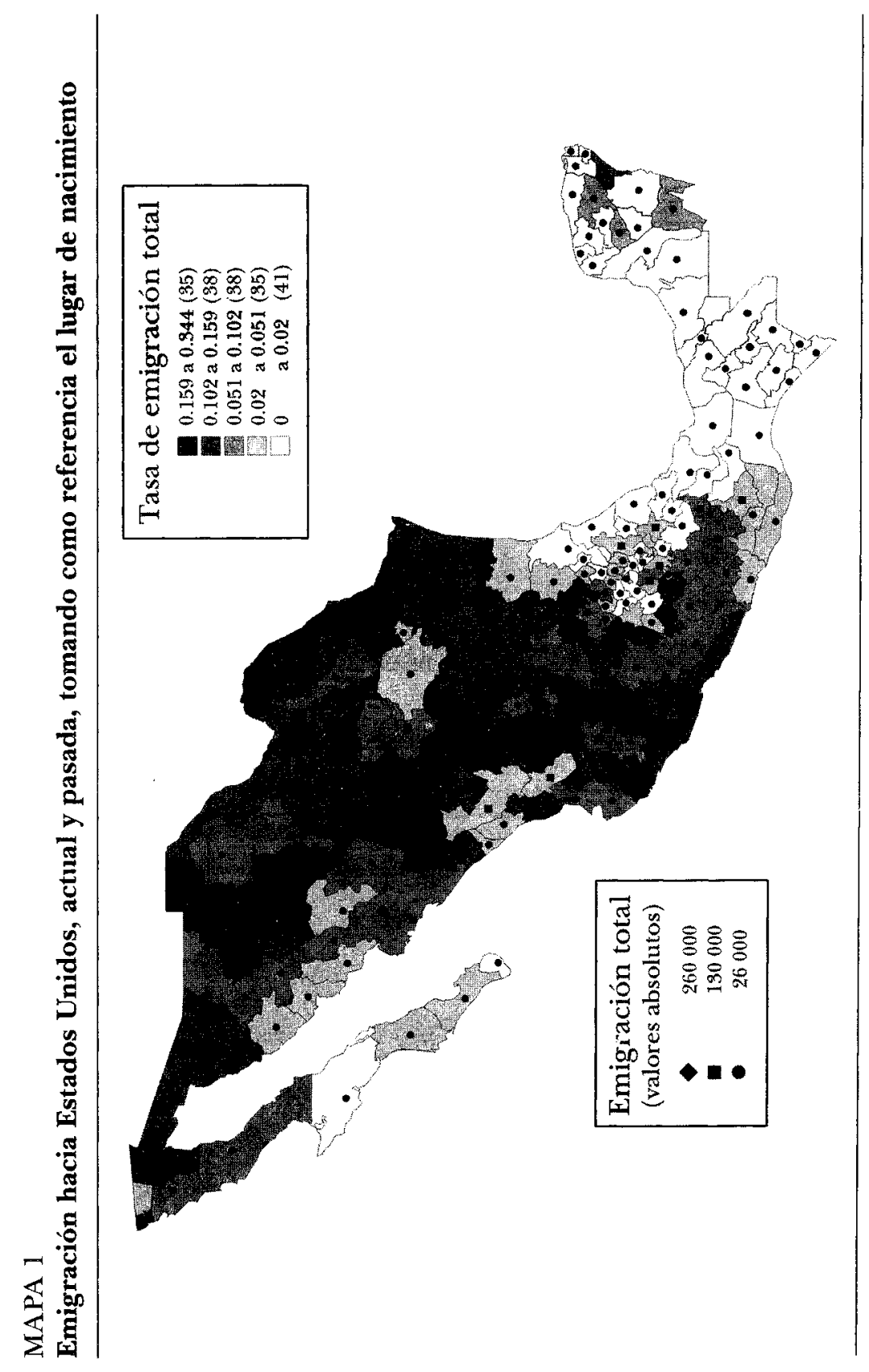




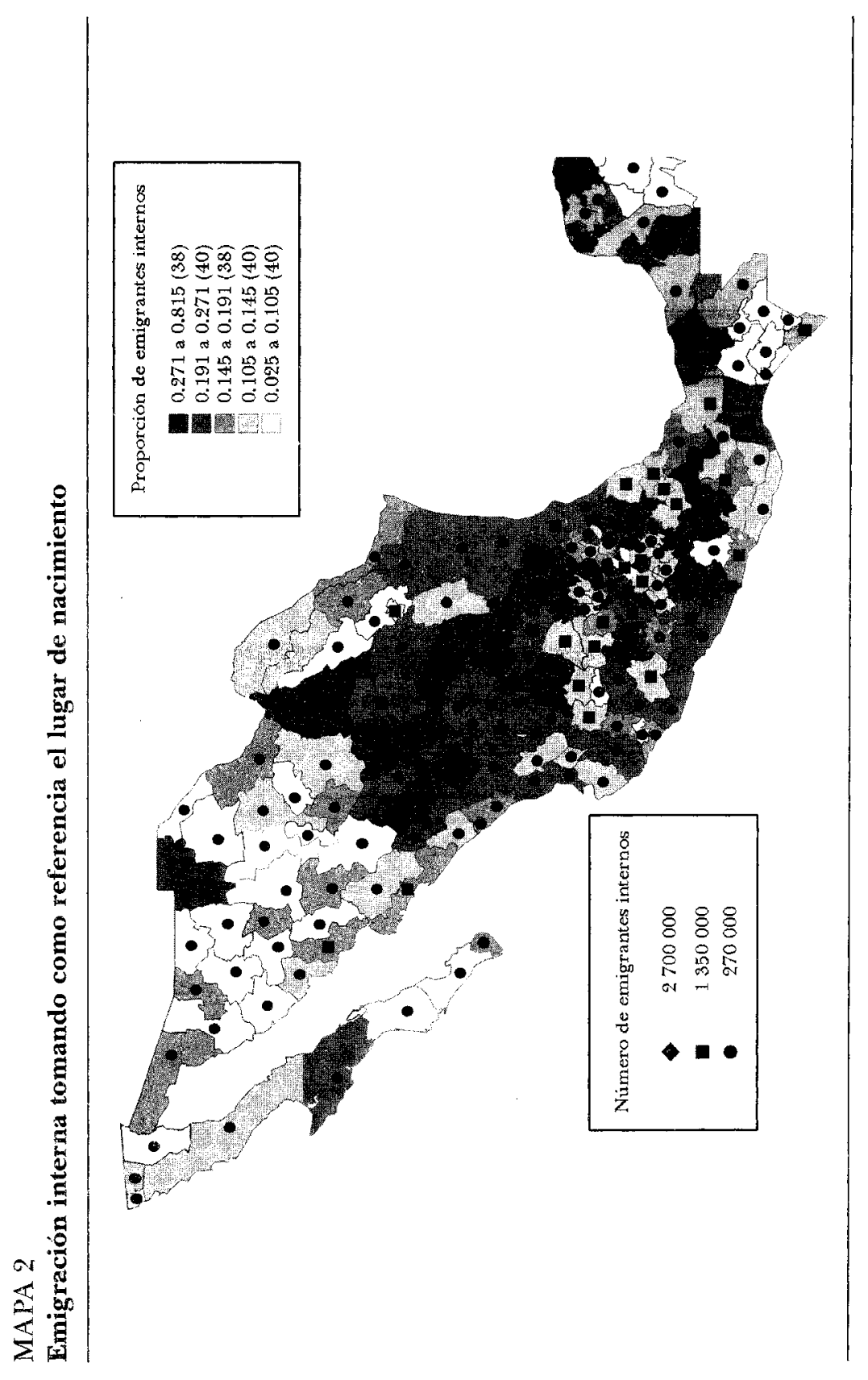




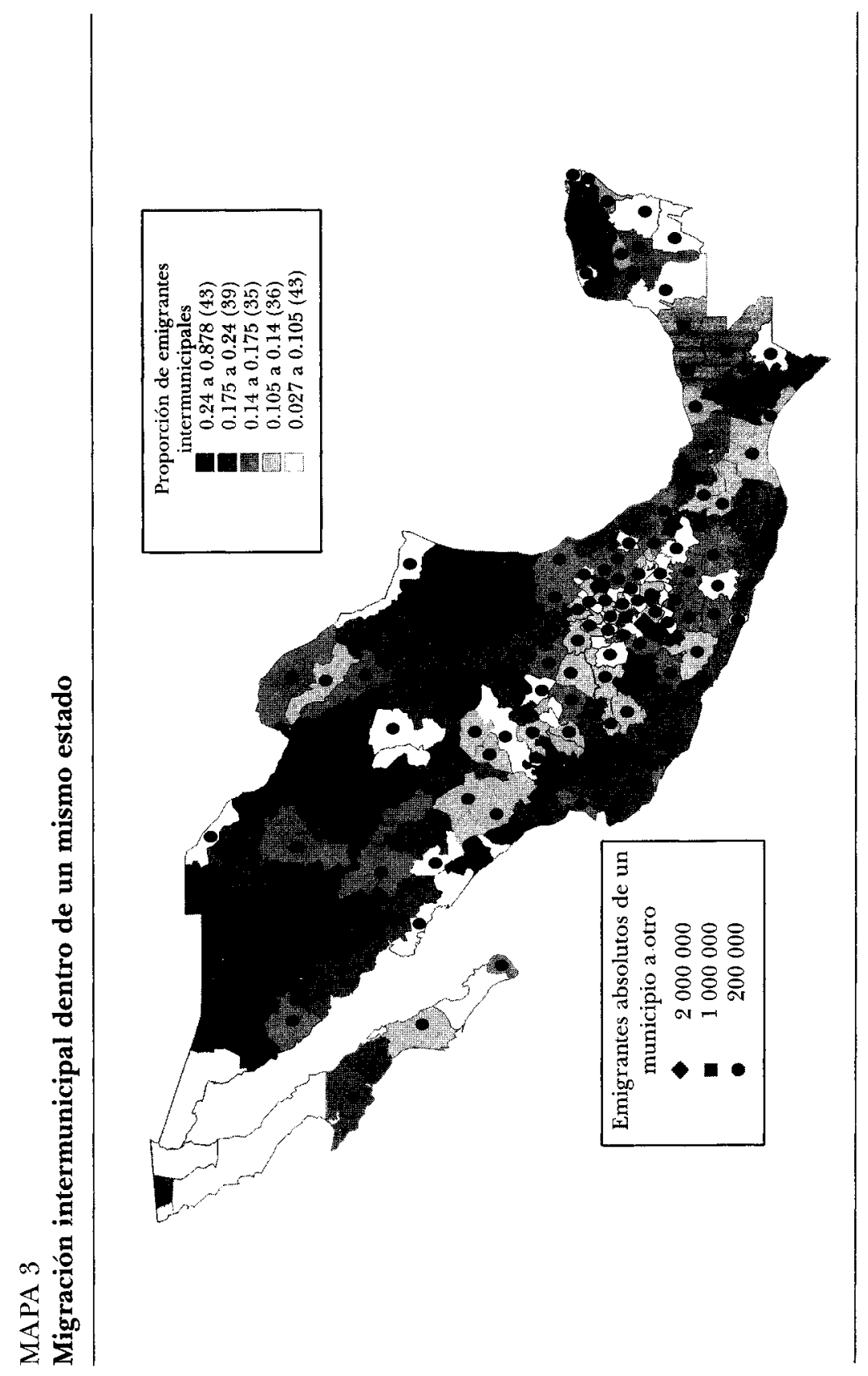


rales o socioeconómicos sean los mismos para todas. Los lugares no influyen con la misma fuerza en los tres casos.

Cabe señalar aquí algunas características representativas de la distribución geográfica mexicana de la emigración internacional. Las regiones con mayor grado de propensión son antes que nada las del occidente de México y, en menor grado, las septentrionales. Desde hace ya más de un siglo, el movimiento de los trabajadores hacia Estados Unidos suele provenir de las regiones del occidente, particularmente alrededor de Jalisco, así como de las regiones que se poblaron durante la prosperidad minera (de Zacatecas a San Luis Potosí), que hoy día atraviesan por una severa crisis. Estos territorios se encuentran en el límite del México árido -correspondiente al eje neovolcánico- donde las lluvias aún permiten cultivos de temporal, aunque solamente durante una breve temporada húmeda. Los grandes reclutamientos de temporeros, como el programa bracero, aprovechan una mano de obra que se vuelve disponible debido a una prolongada temporada seca, justo en el momento de las cosechas en California. De tal suerte que el clima, gracias a esta concordancia, ha contribuido ampliamente a la génesis de estas redes. En efecto, si bien la mitad del territorio mexicano, la cual presenta una escasa participación migratoria, se encuentra a una mayor distancia de Estados Unidos, dicha porción del territorio corresponde también a un clima húmedo tropical en el que se atenúan los contrastes entre las estaciones. El mapa sugiere además una influencia adicional que se irradia alrededor de las capitales regionales - de Hermosillo, Monterrey y sobre todo del sistema urbano central: México, Puebla, Guernavaca, Toluca...-, las cuales parecen compensar, en cierta medida, la atracción del extranjero sobre las poblaciones de sus alrededores. Cabe finalmente destacar un aspecto relevante de la distribución espacial de la migración internacional que no se ajusta a una función normal, sino más bien exponencial, sobre todo hacia los valores elevados. Aunque esperemos una distribución normal de las proporciones de emigrantes (no de su número absoluto), esta distribución sugiere más bien un encadenamiento multiplicativo, es decir que las regiones que registran una fuerte participación migratoria tienden a exagerar el éxodo más allá de lo que se podría normalmente esperar, e inversamente. Este efecto acumulativo podría reflejar la presencia de las redes migratorias, una particularidad que no existe en el caso de la migración interna. 


\section{Correspondencias regionales}

¿Qué panorama nos ofrece el mapa del éxodo? La manera más rápida de responder a esta pregunta consiste en analizar las correlaciones ${ }^{8}$ entre las tasas de emigración observadas y las características regionales. Reconozcámoslo de entrada: los mapas de emigración hacia Estados Unidos parecen en gran medida únicos. Solamente muestran raras y débiles similitudes con las configuraciones espaciales de las características tanto naturales, como demográficas o de la actividad económica. Aun las mejores estimaciones son poco precisas (los coeficientes de correlación raramente sobrepasan 0.5 ), y en ocasiones ofrecen explicaciones triviales.

\section{El medio natural}

Basta con una simple mirada en el mapa de la emigración internacional para advertir la influencia de la distancia respecto a la frontera con Estados Unidos, distancia también vinculada con el riesgo agrícola provocado por los déficit pluviométricos o por la duración de la temporada seca. En primer lugar hemos examinado una serie de indicadores del medio físico procurando controlar la influencia prevista de la distancia para distinguirla de la de los otros factores. A continuación presentamos la lista de los indicadores naturales o espaciales examinados, la cual es a propósito un poco larga por ser exploratoria, con el fin de ilustrar la utilidad potencial de los Sistemas de Información Geográfica:

-La medición de la distancia directa (a vuelo de pájaro) entre la frontera y la unidad espacial considerada permite observar lo que se debe a la distancia dentro de la graduación norte-sur de la emigración, así como controlar esta influencia cuando otros fenómenos (aridez o educación, por ejemplo) presentan una configuración similar.

-La distancia media entre cada unidad de la cuadrícula ${ }^{9}$ a los

${ }^{8}$ Cabe insistir: estas correlaciones miden el grado de similitud entre los mapas. El hecho de que los atributos sean la base de las mediciones individuales podría inducir a pensar que las mismas correlaciones regionales permiten caracterizar a los emigrantes y discernir los determinantes de la migración. No es así debido en parte a una mayor similitud entre los habitantes de una misma región (correlación ecológica).

${ }^{9} \mathrm{La}$ cuadrícula utilizada es una división regular del territorio mexicano que aquí nos sirve para ajustar a una retícula cuadrada (de $8 \times 8 \mathrm{~km}$ ) distintas medidas de los factores naturales provenientes de divisiones muy dispares del espacio. 
principales ejes de comunicación nos pareció ser un buen indicador sencillo del factor de aislamiento, decisivo para el desarrollo de alg unas actividades económicas; se calcula una distancia media por cada región.

- La densidad demográfica regional se calculó directamente con base en el Sistema de Información Geográfica: la presión del poblamiento suele ser considerada como un factor de expulsión.

-Se clasificó la altitud media de la región en tres grandes pisos climáticos susceptibles de revelar el contraste entre la costa y los altiplanos así como sus respectivas formas de población.

-La pendiente media, calculada en cada unidad de la cuadrícula, mide "lo accidentado" del terreno lo cual puede representar un gran obstáculo para la intensificación de los cultivos y las formas de poblamiento.

-Se recalcularon las precipitaciones medias de la región interpolando las curvas isoyetas.

A estos indicadores se agregaron medidas producto de una interpretación y reclasificación del inventario del medio natural:

- Se elaboró un índice de aridez de acuerdo con el balance higrométrico mensual (precipitación menos evapotranspiración) que indica la duración de la temporada seca.

-Se estimó un factor de transformación antrópica del medio ambiente, de acuerdo con una nueva clasificación del manto vegetal, utilizando una escala graduada.

Entre los tres tipos de migración analizados, sólo el que se dirige a Estados Unidos tiene que ver en algunos aspectos con el contexto geográfico o climático, ya que las movilidades internas y municipales ${ }^{10}$ muestran una independencia casi total con respecto a estas características. Además, las similitudes espaciales son escasas: no se observa ninguna asociación significativa entre la migración internacional y la densidad demográfica, ni con la intensidad de la transformación antrópica del medio ambiente, la cercanía a las redes de carreteras, o el aspecto montañoso. Resulta más clara la asociación con la aridez (duración de la temporada seca) y la escasez de lluvias: tratándose del valor transformado de la migración internacional acumulada, el coeficiente de correlación es $\mathrm{r}=-0.63$ con las precipitaciones medias, un poco menos en el caso del índice de aridez $(r=0.5$, estimaciones ponderadas); estas débiles asociaciones se deben de

${ }^{10}$ La única movilidad que disminuye notablemente cuando aumenta la distancia hacia la frontera norte es la municipal, mientras que la proximidad de los ejes carreteros principales sólo la favorece muy ligeramente. 
tomar en serio puesto que son relativamente importantes en comparación con las que nos encontraremos a todo lo largo de este análisis. En realidad la progresión de la aridez se combina con la cercanía a Estados Unidos, siendo este último efecto más susceptible de incitar a la migración que la pluviometría. Sin embargo la aplicación del cálculo de las correlaciones precedentes, controlando la distancia a la frontera, no modifica en forma radical la asociación entre las precipitaciones, la aridez y la magnitud relativa del éxodo $(r=-0.51 \mathrm{en} \mathrm{vez}$ de $-0.63 ; 0.41$ en vez de 0.5 ) cuyos efectos no dejan de ser significativos. De hecho, el México húmedo sí coincide con las regiones en las que casi no hay éxodo: Veracruz, Chiapas, Yucatán. ¿'Tendrán la agricultura y sus carencias alguna influencia en el éxodo? La tuvo y tal vez la siga teniendo hoy día. Lo seguro es que la existencia de una prolongada temporada seca invernal ha facilitado indudablemente el reclutamiento de los braceros y probablemente contribuido al progresivo fortalecimiento de las redes migratorias.

\section{Emigración y población}

La emigración -sobre todo la internacional- es selectiva, de modo que se debería notar la ausencia de los expatriados en las poblaciones afectadas por el éxodo: por ejemplo, el que se vayan los hombres en edad de trabajar debería de hacer resaltar la población femenina o la de edad avanzada. Estaríamos más interesados en descubrir posibles contextos demográficos favorables, o al menos asociados a la emigración: ¿̇e reclutarán más migrantes en regiones urbanizadas o en las indígenas?, ¿̇entre las poblaciones más prolíficas o las más católicas? Una vez más, son escasas las asociaciones geográficas, por lo que nos limitaremos a resumirlas de manera concisa.

De una región a otra, es casi imperceptible el efecto de las emigraciones sobre la proporción de jóvenes y adultos en edad activa. En cambio es más visible sobre la de los ancianos: la proporción de personas mayores de 65 años aumenta considerablemente, en primer lugar, con la migración internacional y luego con la municipal, pero no con la nacional. Uno de los indicadores regionales más sensibles a la emigración es el índice de masculinidad, sobre todo entre los 20 y 24 años, edad para la cual cerca de la mitad de la variación ${ }^{11}$

11 Proporción bruta de emigrantes internacionales, correlación calculada con los atributos ponderados de la población de más de 12 años. 
regional de la migración internacional coincide con una baja relativa de la presencia masculina, aunque las migraciones internas casi no alteran este equilibrio.

No se observa similitud significativa alguna entre los diversos grados de urbanización ${ }^{12}$ regional y las mediciones de la migración. De haber sido posible, hubiese sido más instructivo analizar los efectos de la urbanización basándose en el lugar de residencia y no en el de nacimiento.

Una oposición hasta ahora no observada aparece entre las tierras de mayor tradición católica y los territorios indígenas: ${ }^{13}$ en efecto, los habitantes de las primeras se muestran más propensos a la migración internacional que el conjunto de los mexicanos, mientras que las poblaciones de las zonas indígenas se expatrian en menor medida. Si bien estas preferencias desaparecen en el caso de las migraciones municipales e internas, es posible que esto se deba a una simple coincidencia histórica: las poblaciones indígenas se concentran en el sur, particularmente en Chiapas y en Yucatán, lejos de las influencias norteñas y de la atracción del trabajo en el extranjero. ¿Se deberán estas diferencias a la cercanía de Estados Unidos? Las zorrespondencias cartográficas cambian poco cuando se controla la distancia a la frontera (el coeficiente parcial de la religión católica es entonces de 0.46).

Hemos visto que la distribución geográfica de la emigración inernacional se opone a la de la emigración interna, pero ccómo se somparan éstas con la de la inmigración? No aparece ninguna corespondencia estadística clara entre las regiones escogidas por los nmigrantes y aquellas que dejaron los emigrantes, ya sea con desti1o a Estados Unidos o a otros estados de México. Aunque la relación o es lineal, se observa una clara concentración hacia los valores sajos de la emigración relativa cuando la inmigración interna alcana niveles elevados.

Para poder encontrar una incidencia de los altos índices de creimiento demográfico debemos considerar a las mujeres que se enuentran al final de su vida fértil, cuyos hijos entran hoy a la edad de rabajar y por ende de emigrar. Una generación prolífica, beneficia-

\footnotetext{
12 Tres indicadores fueron examinados: la proporción de personas viviendo en scalidades de más de $2500,20 \mathrm{mil} \mathrm{y} 100$ mil habitantes respectivamente.

${ }^{13}$ Definidos por la proporción de las personas que se expresan o conocen un lioma nativo no hispánico.
} 
da por el descenso de la mortalidad, engendrará una descendencia más numerosa que deberá compartir el patrimonio familiar o los empleos limitados, lo que constituye probablemente una mayor incitación a la emigración, particularmente en las sociedades domésticas. Por su parte, la migración temporal puede influir en la fertilidad de las mujeres jóvenes, ya que tanto la separación de los cónyuges, como el trabajo de las mujeresijóvenes en el extranjero, contribuyen a que se pospongan los nacimientos (aunque éstos se puedan recuperar con el tiempo) o incluso a disuadirlos (Delaunay, 1995). Las cifras apuntan en este sentido: por lo general, en las regiones con mayor migración internacional, el conjunto de las madres tiende a presentar descendencias medias más numerosas para el conjunto de madres $(r=0.38)$, siendo la asociación más clara en el caso de las mujeres que se encuentran al final de su vida fértil, de 40 a 44 años $(\mathrm{r}=0.48)$, y aún más marcada dentro de las generaciones de más de 65 años $(r=0.63)$. En el otro extremo, la relación se invierte en una correlación negativa -aunque de menor amplitud-para las mujeres jóvenes y se va reduciendo con la edad. También se observan estas asociaciones estadísticas en el caso de la migración interna entre los estados, pero no para la movilidad más cercana entre los municipios. Estas asociaciones estadísticas no constituyen en sí una explicación satisfactoria. Cabe recordar que las sociedades domésticas se han organizado en poblaciones con estructuras estables: los medios de producción se transmitían de una generación a otra, sin que aumentara la población.

La transición demográfica viene a trastornar este equilibrio secular: dado que padres e hijos viven más tiempo, son cada vez más numerosos los jóvenes adultos que demandan los recursos necesarios para su subsistencia. Conjuntamente, hemos demostrado que las familias mexicanas que radican en Estados Unidos reúnen a dos o tres veces más parientes colaterales que las que permanecen en México (Delaunay, 1995), lo que sugiere una estrategia de las familias numerosas en favor del exilio. Pero a esta explicación en términos de generación se opone la simple particularidad histórica de un occidente católico y fértil, en el cual existe desde hace mucho tiempo cierta emigración hacia Estados Unidos. No obstante, al controlar la incidencia de la religión católica, ${ }^{14}$ vemos que las similitudes espacia-

${ }^{14} \mathrm{Al}$ introducir la variación regional de la proporción de personas que declaran ser católicas. 
les entre las antiguas tasas de fertilidad y la emigración se mantienen al mismo nivel. Las que sí cambian, hasta caer en un nivel no significativo, son las parideces de las mujeres jóvenes. Esta excepción parece indicar que la migración constituye un mayor obstáculo para la nupcialidad que para la fecundidad, con un efecto indirecto sobre los primeros nacimientos. Dos características suplementarias de las regiones de expulsión corroboran esta observación: un déficit de los hombres que entran en edad de tener hijos, así como una mayor proporción de solteros.

Ya que hablamos de nupcialidad, cabe señalar que se establece una relativamente buena correspondencia numérica entre el mapa de la unión libre y la distribución geográfica de la migración internacional $(r=0.55)$, lo que no ocurre con las dos movilidades internas. Esto viene a completar la precedente observación ya que la fecundidad de las mujeres jóvenes aumenta en las regiones favorables a la unión libre. ${ }^{15}$ Esta correspondencia regional constituye una pista interesante para el estudio de la dimensión familiar del éxodo: nos lleva a preguntarnos si el contexto social que favorece la unión libre no debilita la solidaridad familiar, tan activa en la práctica migratoria hacia el extranjero. No aparece la respuesta en las cifras disponibles; cuando son bajos los niveles de unión libre todas las situaciones migratorias son posibles, y cuando aumentan, hay menos éxodos masivos.

La forma más básica de educación, la alfabetización, no parece afectar la distribución espacial de la emigración (la medida de la asociación es significativa aunque débil). Los que sí se ven más afectados ${ }^{16}$ por el éxodo, son los lugares en los que la proporción de masculinidad de los analfabetos es elevada, es decir en los que la ventaja de los hombres disminuye hasta el punto de invertirse en favor del sexo femenino en el caso de las nuevas generaciones. Esta situación es un rasgo característico del norte de México; sin embargo, sólo se atenúa moderadamente en el momento de controlar la variable por la distancia a la frontera, debido en parte a que la desventaja masculina es más occidental que septentrional. Dado que la alfabetización

\footnotetext{
${ }^{15}$ La correlación entre el mapa de la unión libre y el de las parideces en los jóvenes alcanza el valor de 0.67. Sin embargo, ¿̇será suficiente la presencia de la unión libre para explicar el efecto negativo de la migración sobre su fecundidad? No totalmente: el coeficiente de correlación parcial (es decir, controlando el efecto de la unión libre) entre la migración acumulada y la paridez alcanzada entre los 15 y los 19 años se reduce a la mitad pero sigue siendo negativo y significativo.

16 Se observa un coeficiente de $r=0.57$ para las tasas transformadas de la prosorción de emigrantes.
} 
en sí misma no parece incitar a la migración, no podemos considerar que este desequilibrio cree un contexto propicio para el éxodo. ¿No se debe más bien considerar que una fuerte competencia femenina en el mercado del trabajo tiende a empujar a los hombres al exilio o que éstos, al tener desde muy temprana edad la intención de irse a trabajar en el extranjero, descuidan su educación?

Al observar una notable disminución de la emigración en los lugares donde es mayor el nivel de asistencia escolar entre los 15 y 19 años, nos percatamos de que no es tanto el nivel de los estudios el que disuade el éxodo ${ }^{17}$-al favorecer por ejemplo la creación de empleos locales-, sino que éste se ve aplazado por una escolaridad más tardía, ${ }^{18}$ a una edad en la que se puede escoger entre estudiar o emigrar. Una vez más las cifras no aportan ninguna certeza, ya que resultan escasas las similitudes cartográficas entre la educación y la migración; con todo, reflejan una menor motivación inicial en los lugares que cuentan con mejores niveles educativos. Esta tendencia se registra también en la migración interna de los estados.

\section{¿Migraciones económicas?}

Es más que obvia la motivación económica de los mexicanos que emigran a Estados Unidos, pero la pregunta que anima numerosas discusiones acerca de los motivos de la migración internacional consiste en saber si ésta se debe más a la prosperidad estadunidense o a la pobreza mexicana. Si las desigualdades regionales mexicanas determinaran la magnitud de los flujos migratorios, es de esperarse que éstos varíen de acuerdo con las oportunidades locales de empleo, el nivel medio de los salarios o la productividad de los empleados. Pero en realidad ocurre todo lo contrario: son muy limitadas las correspondencias regionales en casi todos los aspectos de la actividad económica. La distribución de la población activa en los princi-

\footnotetext{
${ }^{17}$ Sólo se puede observar una muy modesta correlación negativa entre los estudios superiores o profesionales y la proporción de migrantes, aunque no para los otros índices de emigración (es sumamente probable que los coeficientes sean nulos).

${ }^{18}$ Una vez más, la interpretación de las relaciones se vuelve incierta al presentarse una mayor varianza de las tasas de emigración acumulada conforme aumenta la asistencia escolar. Ello parece ser causado por un tercer factor, la urbanización: las ciudades en las que hay una mayor asistencia escolar tienden a presentar comportamientos más homogéneos. Aunque aquí interviene también un efecto de tamaño, ya que entre más pobladas están, sus estimaciones de la emigración resultan menos sometidas a variaciones aleatorias.
} 
pales sectores de la actividad económica refleja claras especializaciones regionales -a menudo complementarias-, pero prácticamente ninguna similitud con la emigración ya sea nacional o internacional. No es mayor la emigración en las regiones en las que predomina la actividad agrícola, ni menor en las regiones en las que se ha desarrollado la manufactura. Las dos únicas tendencias observables, significativas aunque muy reducidas, conciernen a la movilidad intermunicipal ligeramente contenida por las actividades comerciales, así como al sector de la construcción un tanto estimulado en los lugares donde es más intensa la migración internacional.

Con todo, hemos de reconocer que carece de rigor la comparación entre las estadísticas migratorias y las del empleo: en efecto, estas últimas se basan en declaraciones personales, y a su imprecisión se suma la incertidumbre del desfase entre las poblaciones nativas, utilizadas para el cálculo de las tasas de emigración, y las poblaciones residentes, para el cálculo del empleo. De modo que señalaremos cautelosamente que la tasa de desempleo varía -aunque débilmente- a la par de la emigración internacional (el coeficiente de correlación es ligeramente superior a 0.3$),{ }^{19}$ pero en el sentido previsible, es decir que la ocurrencia de las emigraciones aumenta con el desempleo. Esta vaga relación no se mantiene con la movilidad interna, lo que nos inspira ciertas reservas acerca del sentido de la causalidad: se debe tomar en cuenta tanto el hecho de que el subempleo motive la emigración como el que éste sea al mismo tiempo una consecuencia del regreso temporal de los emigrantes internacionales que encuentran dificultades a la hora de reincorporarse a las actividades profesionales. Esta interpretación se ve fortalecida por la relativamente buena similitud que existe entre la distribución geográfica del éxodo y la del índice de masculinidad entre los desempleados; ${ }^{20}$ se trata sin duda de la correspondencia espacial más estrecha en materia económica $(r=0.64$, correlación ponderada). Se destaca un subempleo masculino relativamente más importante en las regiones

19 Correlación calculada para los valores regionales no ponderados de las proporciones de emigrantes internacionales y del porcentaje de la población económicamente ac tiva que declara no tener trabajo.

${ }^{20}$ No se trata del índice bruto de masculinidad sino de uno relativo: es la proporción de desempleados masculinos con respecto a la población masculina que se compara con la misma proporción en el caso de las mujeres. Esta selección permite corregir la desigualdad en el número de personas económicamente activas para uno y otro sexo. 
en las que se registra una emigración masiva de trabajadores, en su mayoría masculina, hacia Estados Unidos. Es probable que las mujeres se vean obligadas a trabajar debido a la ausencia de los hombres pero ello no explica esta coincidencia ya que las tasas de subempleo según el sexo se calculan con base en la población económicamente activa. ¿No será más bien la economía local la que se ha adaptado a la ausencia masculina, al desarrollar oportunidades laborales para las mujeres? (Orozco y Barragán, 1995). Cabe señalar que estas cifras ref lejan un deterioro local de la situación del empleo para los migrantes de retorno, los cuales encuentran en esta dificultad un nuevo motivo para irse de nuevo.

Para compensar la ambigüedad de estas estadísticas provenientes de una autodeclaración, hemos procurado verificar estos resultados ciertamente sorprendentes analizando la distribución geográfica de la actividad económica desde el punto de vista de los establecimientos productivos. ${ }^{21}$ Desgraciadamente, el empleo llamado formal que hemos medido de este modo sólo representa una parte de la actividad, por lo que hemos calculado una relación entre la población que trabajaba en los establecimientos registrados en 1989 y la población nativa de más de 12 años estimada por la Enadid en 1992; este indicador aproximativo nos da una idea de la magnitud del sector informal y del subempleo. La influencia no es muy grande pero sólo contribuye a moderar los movimientos migratorios internos, y no los que se dirigen hacia Estados Unidos. Las estadísticas económicas de las empresas miden la producción per cápita y la remuneración por empleado, es decir una estimación de la productividad individual y de los ingresos que se pueden esperar de ella. El censo de 1990 , por su parte, registra los ingresos declarados por cada persona. Ahora bien, uno de los resultados inesperados de este estudio es que ninguno de los indicadores formulados para medir los ingresos y las productividades individuales varía en función de las mediciones de la movilidad. Si bien algunas de las correlaciones son significativas debido al gran número de regiones existentes, su amplitud es tan reducida y su sentido es tan incierto (varían de una tasa a la otra, cambian de sentido según se recurra o no a ponderaciones), que no se puede llegar a ninguna conclusión definitiva.

\footnotetext{
21 Establecimientos de los siguientes sectores: manufactura, extracción, comercio y servicios; esta clasificación no toma en cuenta la agricultura, tampoco los bancos ni la administración.
} 
Un modelo

Por carecer de fundamentos teóricos, esta lectura "a ciegas" no cumple con nuestras expectativas. Entre otras razones, porque el análisis de las similitudes cartográficas que existen entre la emigración y los contextos regionales no toma en cuenta las similitudes que estos últimos presentan entre sí; algunas "influencias" perderán algo de fuerza en cuanto se controlen las que corresponden a varios contextos. Sólo mencionaremos aquí las asociaciones más consistentes de la revisión exploratoria; hemos procurado antes que nada separar aquellas que son susceptibles de ser el producto -más que la causa- de la emigración internacional.

Tratándose del medio físico - el cual desde luego no recibe ninguna influencia de la movilidad-, sólo tomaremos en cuenta la distancia a la frontera y las precipitaciones. La implantación del catolicismo no data de este siglo, pero recientemente en algunos lugares, ha estado perdiendo terreno frente al protestantismo. La práctica de la unión libre y la fecundidad de las mujeres entradas en años preceden tanto a los flujos migratorios que se observan hoy día como al desequilibrio del analfabetismo según el sexo cuando se aplica este indicador a los ancianos. Asimismo, no son los índices de masculinidad de los jóvenes adultos los que crean un contexto favorable al éxodo, sino que éstos son más bien la consecuencia del fuerte componente masculino de estos flujos migratorios. Resulta delicada la cuestión de los desequilibrios entre los desempleados hombres o mujeres, por lo que sólo introduciremos este dato hasta el final. El ajuste del modelo - al igual que los coeficientes de correlación- se llevó a cabo mediante el método de los mínimos cuadrados, ponderados por la población nativa de más de 12 años en 1992 (estimación de la Enadid), lo que permite restituir el peso demográfico de cada región y corregir la mayor varianza de las estimaciones relativas a los lugares poco poblados.

Tras descartar media docena de observaciones extremas, poco convincentes a la luz de las pruebas realizadas, se obtiene un nuevo ajuste que conduce a eliminar dos variables de menor incidencia: la distancia a la frontera y la proporción de católicos. De hecho la cercanía a Estados Unidos no contribuye de manera segura a la variación de la tasa de emigración, mucho menos en todo caso que otras características regionales, las cuales presentan también una cierta graduación norte-sur, particularmente las precipitaciones medias. En nues- 
tro modelo sólo hemos conservado esta última característica física, debido a que consideramos que estas dos variables están estrechamente ligadas. Siguen siendo muy significativas las dos medidas de los índices de masculinidad, tanto entre los analfabetos como en la población desempleada, aunque a veces resulte difícil distinguir el sentido de la causalidad. Luego aparecen, por orden, la paridez de las generaciones anteriores y la unión libre, dos características mucho más decisivas que la tradición o la práctica religiosa católica. Estos tres aspectos de la reproducción y de la formación familiar parecen tener fundamentos comunes, que sin duda constituyen un componente familiar decisivo. Los parámetros del modelo final (el que sólo ha conservado las variables significativas) están resumidos en el cuadro 1. Recordemos que la variable independiente, las tasas de emigración acumulada, se expresan en una forma logito y los residuos presentan una distribución normal.

\section{CUADRO 1}

Características de las estadísticas de las variables del modelo

\begin{tabular}{|c|c|c|c|c|c|c|}
\hline Variable & Parámetro & $\begin{array}{l}\text { Desviación } \\
\text { estándar }\end{array}$ & $\begin{array}{c}\text { Tpara } \\
\text { hipótesis } \\
\text { nula }\end{array}$ & Pro $>(T)$ & $\begin{array}{c}\text { Parámetro } \\
\text { estandarizado }\end{array}$ & $\begin{array}{l}\text { Inflación } \\
\quad \text { de la } \\
\text { varianza }\end{array}$ \\
\hline Constante & -6.308071 & 0.4916 & -12.830 & 0.0001 & 0.000 & 0.000 \\
\hline $\begin{array}{l}\text { Precipitaciones } \\
\text { medias }\end{array}$ & -0.000778 & 0.0001 & -6.413 & 0.0001 & -0.319 & 1.615 \\
\hline $\begin{array}{l}\text { Parideces } \\
\text { anteriores }\end{array}$ & 0.256796 & 0.0814 & 3.153 & 0.0019 & 0.165 & 1.791 \\
\hline Unión libre & -0.035635 & 0.0132 & -2.689 & 0.0079 & -0.147 & 1.949 \\
\hline $\begin{array}{l}\text { Equilibrio } \\
\text { hombres/mujeres } \\
\text { en desempleados }\end{array}$ & 0.008731 & 0.0015 & 5.810 & 0.0001 & 0.287 & 1.595 \\
\hline $\begin{array}{l}\text { Equilibrio } \\
\text { hombres/mujeres } \\
\text { en los analfabetos } \\
\text { (de } 65 \text { años y más) }\end{array}$ & 0.022490 & 0.0034 & 6.430 & 0.0001 & 0.309 & 1.510 \\
\hline
\end{tabular}

Nota: $73 \%$ de la varianza "se explica" por el modelo (.7245 para el $\mathrm{R}^{2}$ ajustado). 
Las tres cuartas partes de la variación son predichas por el modelo (el $\mathbf{R}^{2}$ ajustado es de .72), lo que no significa que las variables escogidas sean necesariamente la causa de esta variación "explicada"; es probable que otros factores influyan indirectamente en todo ello, por lo que resulta difícil determinar el sentido de la causalidad de algunas variables. Convendría más bien averiguar si la configuración espacial de los residuos nos puede revelar efectos regionales que los censos omiten. Hemos de explorar dos pistas. La contribución a la migración internacional de las principales ciudades fronterizas (así como de Tamaulipas) es mucho mayor de lo que se podría pensar al observar sus características naturales o socioeconómicas; ahí se reflejan sus relaciones privilegiadas con Estados Unidos y particularmente la importancia de los commuters entre ambos países. Paralelamente, se destacan algunas regiones de la frontera meridional, lo que podría corresponder a falsas declaraciones acerca del lugar de nacimiento por parte de los centroamericanos que transmigran. La segunda observación se refiere a los alrededores cercanos de la capital, así como a numerosos centros urbanos del país (Monterrey, Saltillo, Ciudad Obregón, Hermosillo, Aguascalientes, Veracruz...) que moderan la influencia de los factores contextuales al desviar una parte de la emigración internacional. Si bien este efecto es muy visible en el mapa, no aparece en las cifras de la urbanización debido a que otras ciudades no desempeñan esta función (particularmente las de la frontera o de la costa meridional del Pacífico). El corolario de esta observación es que numerosos territorios que se encuentran lejos de los grandes ejes de comunicación y de sus núcleos urbanos registran una emigración internacional más intensa de lo que se hubiera podido prever en función de sus características. De manera paradójica serían los lugares más distantes de los flujos económicos de las grandes redes, aislados del resto de México, los que serían los más propicios a una emigración lejana.

\section{La percepción individual de las influencias contextuales}

Hasta ahora sólo hemos analizado las entidades regionales. Las asociaciones estadísticas que hemos destacado, sobre todo las más sorprendentes (que tuvimos que descartar), nos han permitido explorar la geografía del éxodo hacia Estados Unidos. Pero en este nivel agregado de observación, las correspondencias estadísticas establecidas 


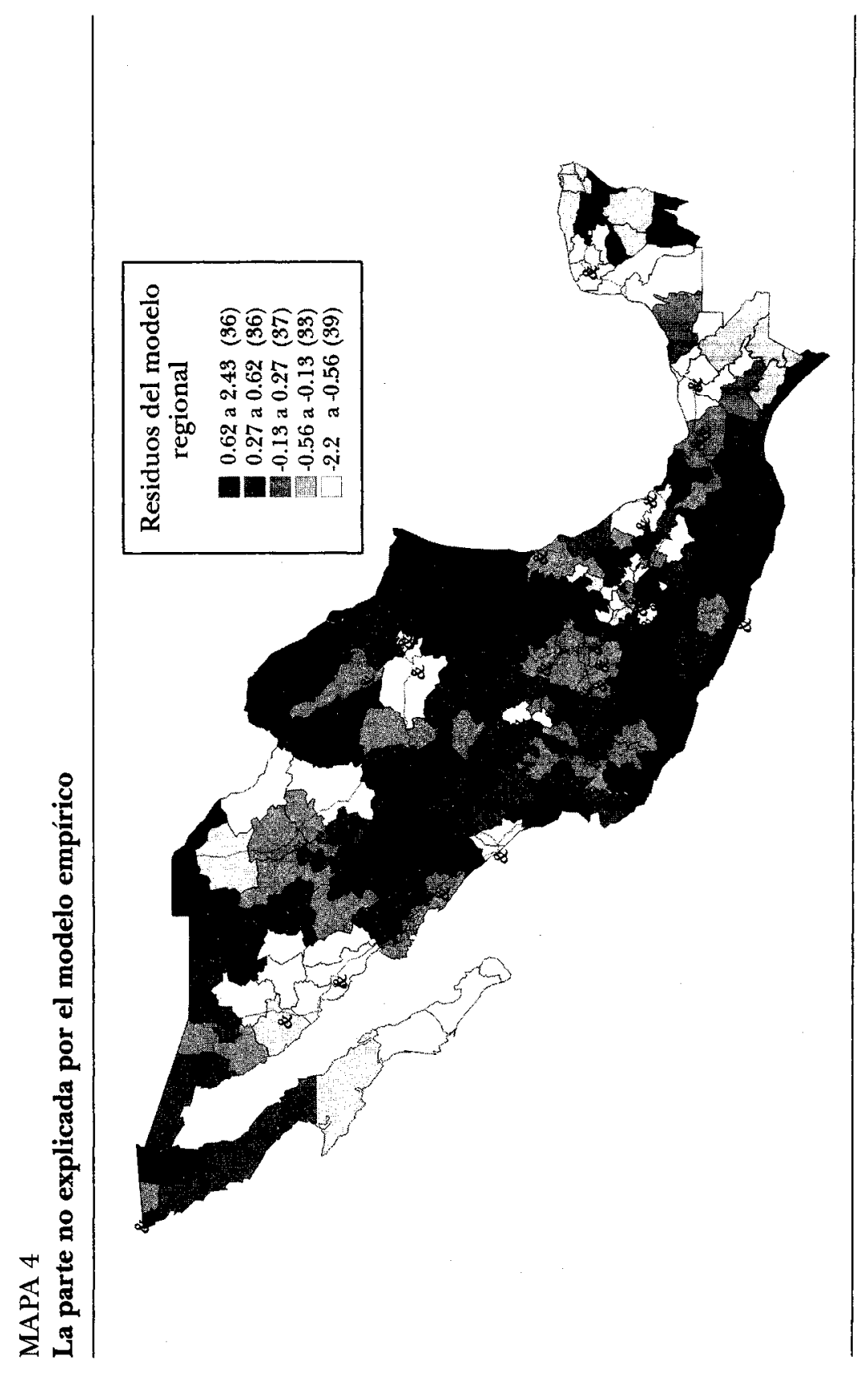


no demuestran gran cosa respecto a las influencias contextuales en la decisión de migrar, la cual resulta ser antes que nada una decisión individual. Sabemos desde Robinson que las correspondencias estadísticas observadas en un nivel regional pueden aminorarse en el momento del análisis individual, así como también pueden aparecer otras.

En la presente sección procuraremos evitar la agregación regional de las observaciones individuales, la cual acarrea una gran alteración de la información; esto equivale a conservar la estructura jerárquica de la información y a asociar los niveles individuales, familiares o regionales. Tanto los hechos como la teoría privilegian el carácter personal de la decisión de emigrar; el análisis exploratorio anterior sugiere el efecto decisivo del ámbito familiar, pero el objeto de nuestro estudio sigue siendo el impacto de las influencias regionales. El análisis multinivel, gracias a su mayor rigor estadístico, desemboca en una formulación más rigurosa de las influencias contextuales, poco susceptibles de ejercerse directamente en la emigración, sino más bien por medio de mecanismos individuales. El desempleo de una persona es una incitación directa a la emigración, mas no el subempleo regional; pero cuando éste persiste, puede haber contribuido a desarrollar una cultura migratoria en las familias. Hemos de esperar que el contexto se manifieste a través de factores individuales. El análisis jerarquizado tiene como meta conciliar todas las escalas micro y macro, el enfoque individualista y el estructural -que resultan más complementarios que antagónicos-, tratando de discernir entre la decisión personal y las determinaciones sociales, contextuales o estructurales en los mecanismos migratorios.

\section{Exigencias y limitaciones estadisticas}

El análisis multinivel eleva las exigencias estadísticas y aumenta la complejidad del análisis; en el caso mexicano, diversas características de la información limitan sus alcances.

La primera dificultad consiste en elegir los niveles yuxtapuestos de observación, debido a que éstos multiplican el número de variables consideradas por el modelo. Esta complicación presenta dos aspectos: primero el teórico, puesto que esta selección debe basarse en algunas hipótesis sobre la naturaleza de las relaciones entre las unidades de los distintos niveles (no sólo por la interacción de las varia- 
bles individuales, sino por la manera en que se ejercen, por ejemplo, las influencias contextuales en una decisión familiar). Y luego el práctico, ya que la información contextual se suele generar para un gran número de unidades y de coberturas, sobre todo cuando provienen de un Sistema de Información Geográfica (diferentes cortes del medio físico, cuadriculado de las fotos de satélites). Es cuando surge el dilema entre la intención de simplificar -agregando al nivel superior-, y el apego a una exactitud que puede llegar a ser estorbosa. En el caso que nos interesa, las medidas del medio físico son agregadas en la unidad regional; tal vez hubiese resultado interesante tomar en cuenta el contexto de los lugares de destino o las diferencias entre las regiones de origen.

Un segundo conjunto de complicaciones más específicas radica en la naturaleza transversal y en las limitaciones estadísticas de la encuesta que documenta este estudio. La Enadid sólo describe a la población emigrante de manera somera: nos proporciona un número de personas ausentes, pero sin llegar a caracterizarlos, a partir de los informantes que se quedaron en México; de hecho, no se sabe nada acerca de sus hogares. En cambio, conocemos con lujo de detalles la encuesta de los migrantes de retorno, interrogados en México. Para introducir las características individuales en el análisis regional debemos descartar a los emigrantes que se encuentran actualmente en Estados Unidos ${ }^{22}$ y conservar únicamente a los que ya regresaron a México. Ello añade una dificultad analítica suplementaria debido a que entre las poblaciones mexicanas sedentarias -que nunca han emigrado a Estados Unidos- y aquellas que han regresado al país con una experiencia migratoria, se deslizan dos procesos selectivos imposibles de diferenciar: la salida y el regreso a México. De modo que las características observadas en el momento de la encuesta se pueden haber adquirido antes de la migración, una vez en el extranjero o después de haber regresado a México; nos falta conocer su calendario preciso y compararlo con el de la migración. Por ende, no pensamos poder discernir lo que ha motivado una emigración o un regreso, ni determinar en qué medida el hecho de haber tenido un empleo en Estados Unidos confiere una ventaja económica o social al momento de la reincorporación del migrante a México. De manera más

\footnotetext{
${ }^{22}$ Debido sobre todo a la escasez de datos relativos a su hogar ya que disponíamos - para los emigrados- de algunas de las características individuales que hemos analizado.
} 
modesta, nuestro objetivo consistirá en examinar las variables contextuales más efectivas pero esta vez desde el punto de vista individual, lo que permite controlar con mayor eficacia algunas características personales decisivas en el riesgo de migrar. Así es conno el análisis regional ha revelado una asociación entre la proporción de migrantes y el índice de masculinidad de la población activa o analfabeta; considerar la edad y el sexo de las personas al mismo tiempo que la educación o la actividad permite una estimación más precisa de estas influencias, ya que se aprovecha toda la información y no sólo los promedios regionales de la composición por sexo.

Al exigir más datos cuantitativos, el análisis multinivel suele implicar una diversificación de sus fuentes. Las estadísticas del censo de 1990 nos proporcionan las principales mediciones socioeconómicas regionales, pero como no nos informan acerca de la migración internacional, no resultan útiles en el nivel individual. En efecto, cabe recordar que la medición del éxodo proviene de la Enadid, la cual menciona la experiencia migratoria de los individuos sin tomar en cuenta numerosas descripciones individuales o domésticas. Esta encuesta no dice nada de los ingresos personales, el origen indígena, el estatus profesional o el empleo. No todas las estadísticas agregadas utilizadas en el análisis espacial podrán ser llevadás a su verdadera dimensión individual, por lo que se vuelve aún más difícil distinguir cuáles son los elementos que determinan una emigración hacia Estados Unidos. Esta última limitación es una razón más para atenerse a una estimación de las influencias contextuales sin dejar de controlar algunas características individuales.

\section{El modelo contextual elemental}

Con la intención de simplificar, propondremos una primera formulación clásica de un modelo contextual, sabiendo de antemano que ésta es insuficiente desde el punto de vista del análisis estadístico. Luego procuraremos introducir, en la medida de lo posible, las técnicas del análisis multinivel para destacar sus ventajas y las aplicaciones que nos permite vislumbrar, así como las dificultades que lo restringen.

La formulación mínima de un modelo contextual consiste en asociar a las medidas individuales - sin tomar en cuenta la estructura jerárquica de los datos- los efectos observados en el ámbito de los hogares y a escala regional. La principal restricción inherente a este 
método elemental es que no se respeta la regla de independencia de las observaciones; en efecto, se repite la misma medición de los niveles superiores de manera idéntica, para los individuos pertenecientes a cada grupo descrito por las evaluaciones de contexto. En otros términos, una medida relativamente rara, efectuada en el nivel superior aparece -de manera errónea- tan detallada como las observaciones de nivel inferior. La variable que intentamos estimar es dicotómica (migrante), que toma el valor de 1 si el individuo, actualmente residente en México, ha tenido una experiencia migratoria en Estados Unidos exclusivamente con fines de trabajo. El ajuste será, pues, de tipo logistico.

Respecto al primer nivel -el de las características individuales-, la Enadid proporciona muy poca información pertinente para comprender la trayectoria migratoria, dado que los individuos interrogados son antiguos emigrantes de retorno al país. Por ejemplo, no se puede justificar una antigua experiencia migratoria con base en las condiciones actuales de actividad, ni tampoco en función de migraciones internas cuyo calendario sólo conocemos parcialmente. Hemos elegido dos variables elementales de control: la edad y el sexo de los individuos. La situación de parentesco dentro del hogar es una información individual decisiva, pero que ya de por sí depende del ámbito familiar. Con el fin de simplificar una nomenclatura de parentesco suficientemente detallada, hemos distinguido al jefe del hogar, su cónyuge, los hijos y ascendientes y finalmente a los otros miembros, ya sean parientes o no.

En el segundo nivel de agrupamiento, el de la familia, el modelo introduce dos nuevos efectos: la paridez media de las mujeres en la familia y una variable de control que registra la participación migratoria actual de uno de los miembros de la familia además del emigrante mismo. La migración mayoritariamente masculina no se puede asociar a la fecundidad de los individuos, por lo que hemos calculado un indicador medio para el hogar, basado en la paridez de cada una de las mujeres que residen en él, esto con el fin de sustituir la medición regional que utilizamos anteriormente. La segunda medición nos ha parecido útil porque la variable dependiente no mide la migración actual, sino la migración pasada de los residentes presentes; además, al interesarse en el involucramiento migratorio del hogar se observa lo que podríamos calificar como efecto de red, o aún más, especialización familiar de la migración. Esta variable se construyó a partir de la pregunta acerca del número de personas que 
normalmente pertenece al hogar pero que se encuentran en el extranjero (tiene un valor nulo en caso de que no se constate ninguna ausencia y el valor 1 si uno o varios miembros están en el extranjero).

Todos los demás indicadores son efectos contextuales regionales; la mayor parte ya ha sido examinada en el análisis agregado, aunque algunos hayan sido simplificados. Se ha conservado la distancia a la frontera norte expresada en centenas de kilómetros, así como la aridez, la cual se determina en función de las precipitaciones clasificadas de la siguiente manera: con menos de $300 \mathrm{~mm}$ de lluvias la región es considerada como árida, entre 300 a $800 \mathrm{~mm}$ como templada y por arriba de los $800 \mathrm{~mm}$ como húmeda. El efecto de las zonas rurales será estimado hasta un límite de 20 mil habitantes. Los ingresos medios de la región serán examinados paralelamente a la remuneración de los empleados en los establecimientos censados; ambas estimaciones provienen de las fuentes censales demográficas y económicas que hemos utilizado anteriormente. Los lugares con más de $5 \%$ de población bilingüe han sido definidos globalmente como zonas indígenas. Hemos agregado dos índices de masculinidad estandarizado ${ }^{28}$ a las medidas propiamente contextuales, debido a su contribución observada en el análisis geográfico, con el fin de averiguar si su influencia se mantiene después de que hayamos controlado el sexo de los individuos. Lo mismo hicimos con la proporción de uniones libres.

El hecho de ser hombre multiplica prácticamente por seis la probabilidad de emigrar, pero tal vez aún más la de regresar. Esta reserva proviene de la observación de una mayor presencia femenina en las estadísticas del stock de la población emigrada. ${ }^{24}$ Las mujeres se ven menos afectadas por el éxodo, pero una vez que se han ido regresan con menor frecuencia que sus compañeros, cuyas migraciones son más bien temporales. En efecto, debido en parte a las oportunidades familiares, las mujeres son más propensas a quedarse en Estados Unidos.

\footnotetext{
${ }^{23}$ Estandarizados en el sentido de que se toman en cuenta efectivos distintos de cada categoría, comparando no los números absolutos sino los relativos, es decir las proporciones de analfabetos según el sexo más que los números absolutos.

${ }^{24}$ Los índices de masculinidad van de 150 hombres/ 100 mujeres para las poblaciones censadas en 1990 a más de 1000 para las poblaciones móviles registradas en los flujos migratorios fronterizos por la Emif.
} 
CUADRO 2

Estimación de los parámetros del modelo elemental, sin tomar en cuenta la estructura jerárquica de la información

\begin{tabular}{|c|c|c|c|}
\hline Efecto & $\begin{array}{l}\text { Estimación de } \\
\text { los coeficientes }\end{array}$ & $\begin{array}{l}\text { Desviación } \\
\text { estándar }\end{array}$ & $\begin{array}{l}\text { Razón de momios } \\
\text { (odds ratio) }\end{array}$ \\
\hline Intersección & $-6.3004^{*}$ & 0.179 & \\
\hline \multicolumn{4}{|l|}{ Efectos individuales: } \\
\hline Sexo masculino & $1.7609 *$ & 0.054 & 5.818 \\
\hline Edades (años) & $0.0076^{*}$ & 0.001 & 1.008 \\
\hline Jefe del hogar & $1.3485^{*}$ & 0.076 & 3.852 \\
\hline Cónyuge del jefe del hogar & $0.4950^{*}$ & 0.091 & 1.640 \\
\hline Hijos o ascendientes & $-0.5159 *$ & 0.079 & 0.597 \\
\hline Otros parientes & $-1.3276^{*}$ & & 0.265 \\
\hline \multicolumn{4}{|l|}{ Efectos familiares: } \\
\hline $\begin{array}{l}\text { Presencia de un miembro de } \\
\text { la familia en EUA }\end{array}$ & $2.6510^{*}$ & 0.033 & 14.169 \\
\hline Paridez media del hogar & $-0.0667^{*}$ & 0.005 & 0.936 \\
\hline \multicolumn{4}{|l|}{ Efectos regionales: } \\
\hline Distancia a la frontera $(100 \mathrm{~km})$ & $-0.0930^{*}$ & 0.008 & 0.911 \\
\hline Tierras áridas (menos de & & & \\
\hline $300 \mathrm{~mm}$ de lluvias) & 0.0921 & 0.087 & 1.097 \\
\hline Clima templado (300-800 mm) & $-0.0921^{*}$ & 0.043 & 0.912 \\
\hline $\begin{array}{l}\text { Zona rural (localidad de } \\
\text { menos de } 20000 \text { habs.) }\end{array}$ & $0.2098^{*}$ & 0.031 & 1.233 \\
\hline $\begin{array}{l}\text { Ingresos medios de la región } \\
\text { (número de salarios mínimos) } \\
\text { Índice de masculinidad de la }\end{array}$ & -0.0540 & 0.037 & 0.947 \\
\hline PEA desempleada & $0.00515^{*}$ & 0.009 & 1.005 \\
\hline $\begin{array}{l}\text { Índice de masculinidad en los } \\
\text { analfabetos mayores de } 65 \text { años }\end{array}$ & $0.0161 *$ & 0.001 & 1.016 \\
\hline $\begin{array}{l}\text { Proporción de uniones libres } \\
\text { Remuneración de los empleados }\end{array}$ & $-0.0345^{*}$ & 0.004 & 0.966 \\
\hline en los establecimientos censados & $-0.0656^{*}$ & 0.010 & 0.937 \\
\hline Zonas indígenas & $-0.6803^{*}$ & 0.052 & 0.506 \\
\hline
\end{tabular}

* Los efectos son significativos a partir de 5 por ciento.

La edad no parece tener una incidencia decisiva, aunque en teoría la probabilidad de emigrar al menos una vez aumenta con ésta. Que el efecto de la edad sea poco se explica por la fuerte concentración de las primeras migraciones en un intervalo corto de edad, entre los 18 y los 25 años. La calidad de migrante, que mide la variable 
independiente estimada aquí, se adquiere pues muy pronto, al inicio de la edad adulta, anulando prácticamente el efecto lineal y a largo plazo de la edad. Cabe añadir sobre todo que el corte transversal de la encuesta mezcla generaciones que tienen distintas historias migratorias y que las más recientes corresponden al considerable incremento del éxodo desde finales de los años setenta.

Al observar el cuadro 2 se destaca el efecto decisivo del parentesco dentro del hogar y sobre todo de la eventual experiencia migratoria de cualquiera de sus miembros. Al contrario de la idea extendida de que los emigrantes son los miembros solteros y libres de obligaciones familiares, más bien son los jefes de hogar los que presentan la mayor probabilidad de encontrarse de nuevo en México después de haber emigrado al exterior al menos una vez ${ }^{25}$ (controlando los efectos del sexo y de la edad): un riesgo multiplicado prácticamente por cuatro con respecto al resto de los individuos, que sigue siendo superior para los cónyuges aunque solamente en $60 \%$, y resulta menor para los otros miembros de la familia. Hay que recordar que estos parámetros miden tanto la probabilidad de una emigración como la de un retorno. Ahora bien, un análisis complementario de la duración de los viajes, basado en la misma encuesta de la Enadid, precisa que si bien los jefes de familia son los más propensos a emigrar, también son los que más fácilmente regresan. Lo que los distingue antes que nada de los demás miembros del hogar, es la brevedad de su estadía en el extranjero, visiblemente restringida por sus obligaciones familiares; en cambio, los viajes se suelen repetir con mayor frecuencia. Por su parte, los miembros cuyo grado de parentesco es más lejano o inexistente, no acostumbran regresar con eljefe del hogar por lo que se les registra con menor frecuencia dentro de la encuesta. Las situaciones intermedias muestran una gradación en la participación en los procesos migratorios que depende de las obligaciones familiares.

$\mathrm{Al}$ aumentar la paridez media de la familia, tenderá a reducir la probabilidad -aunque débilmente- de una decisión migratoria individual. Esta observación no entra tanto en contradicción como parece con el efecto de la paridez registrada en el nivel regional, la cual refleja una clara incitación positiva al éxodo en el caso de la descendencia de las generaciones anteriores; se ha detectado un efecto contrario a la baja en el caso de las mujeres jóvenes. Debido a que éstas

\footnotetext{
${ }^{25}$ Para matizar esta observación cabe señalar que las personas solas son registradas como jefes de hogares unipersonales.
} 
son más numerosas, suele prevalecer la compensación en el nivel de hogar. Aunque no sería el primer ejemplo de un mismo efecto que se ejerce en un sentido opuesto en el nivel agregado e individual (Courgeau, 1994), además resulta lógico que la presión de las nuevas generaciones en los recursos sea más perceptible tanto en el nivel de comunidad como de región.

Tratándose también del ámbito familiar, un efecto se distingue de los demás y por mucho, el de la ausencia de un miembro del hogar que se fue al extranjero. La relación es estrecha: las probabilidades de que un individuo haya trabajado en Estados Unidos se ven literalmente multiplicadas por catorce cuando otro miembro de la familia se encuentra en el extranjero. De hecho, esta relación funciona en los dos sentidos (ya que en muchos casos la experiencia migratoria de la persona presente ha precedido la ausencia del actual emigrante); nos proporciona una medición de la especialización migratoria de algunas familias, no sólo de la existencia de redes sino del remplazo de retornos por nuevas emigraciones. El efecto de incitación familiar es notorio en el caso de los hogares que se quedaron en México ya que la encuesta no incluye las que se fueron completas para "el otro lado".

El impacto de las variables regionales cambia notablemente (como era de esperarse en un modelo modificado), aunque no en forma radical. Se confirma el efecto disuasivo de la distancia a la frontera: cada centenar de kilómetros reduce la probabilidad de una emigración (así como del retorno) en aproximadamente 10\%. En cambio, las precipitaciones no tienen un efecto significativo, aunque no se puede descartar la hipótesis nula (basándose en una clasificación en tres grupos climáticos que van del más árido al más húmedo). La pertenencia a una localidad rural ${ }^{26}$ o población menor de 20 mil habitantes aumenta en $23 \%$ la ocurrencia de una emigración, lo que representa un resultado más contundente y preciso que el precedente. La remuneración media de los empleados y los ingresos medios de la región disuaden la migración, pero de una manera tan escueta que no nos atreveríamos a sacar alguna conclusión al respecto; además la contribución sólo es significativa para la remuneración media de los empleados de los establecimientos censados. Tras haber con-

${ }^{26}$ Esta medida de la ruralidad es más precisa que los indicadores regionales conservados en nuestro análisis regional puesto que la información proporcionada por la Enadid se refiere precisamente a la localidad habitada por los individuos, y no a una media agregada de la presencia de estas localidades. 
trolado la edad, el sexo y la distancia a Estados Unidos, el desequilibrio del índice de masculinidad en lo que concierne tanto al desempleo como al analfabetismo conserva cierta asociación con la migración, sin que sepamos bien por qué. En cuanto a la pertenencia a territorios de tradición indígena, reduce la probabilidad migratoria a la mitad -habiendo controlado otros factores naturales (clima húmedo), económicos (bajo ingresos), geográficos (distancia a Estados Unidos) que pueden ser asociados a la localización indígena-, lo que constituye una confirmación de nuestras conclusiones precedentes.

\section{La formulación de un modelo jerárquico}

A diferencia del análisis geográfico basado en datos agregados, la formulación contextual ofrece la ventaja de conservar la información individual, aunque presenta serias limitaciones en materia de migración internacional. Pero al repetir en forma idéntica las características familiares o regionales para cada individuo perteneciente a estas unidades de nivel superior, se viola una de las hipótesis fundamentaes del análisis estadístico: la independencia de las observaciones. Con el fin de evitar las consecuencias de este error, ${ }^{27}$ se han diseñalo nuevos métodos de estimación. Se presentan bajo varias denomilaciones: en biometría se habla de modelo de "efectos mixtos" o "efecos aleatorios", aunque en las ciencias sociales -particularmente en :ducación- sea más frecuente el término de "modelos jerárquicos" o "modelos multiniveles" (Bryk y Raudenbush, 1992; Goldstein, 1995). Uás allá de una mejor estimación de los efectos individuales en caso le reagrupamientos, este enfoque permite formular y verificar algulas hipótesis acerca de los efectos que pasan de un nivel a otro (de Ina característica regional a un comportamiento individual), y pernite al mismo tiempo discernir la varianza y la covarianza entre los listintos niveles, debidas por ejemplo a los desfases entre los indiviluos o entre las regiones.

En términos de componentes de la varianza, el modelo lineal se uede expresar de la siguiente manera:

Consideremos un nivel 1 individual (i) y un grupo (j) de nivel 2.

27 La repetición de las observaciones da una impresión falsa de precisión de la iformación y produce pruebas estadísticas demasiado optimistas en cuanto a la inciencia de las variables de nivel superior. 
En el nivel individual se puede concebir la relación en términos lineales clásicos:

$$
\mathrm{Y}_{\mathrm{ij}}=\beta_{0 \mathrm{j}}+\beta_{\mathrm{j}} \mathrm{X}_{\mathrm{ij}}+\varepsilon_{\mathrm{j}}
$$

Supongamos luego que la intersección con el eje de las coordenadas varía de un grupo a otro. En su formulación más sencilla (que se refiere al análisis de la varianza), este valor varía en torno a una media general de los grupos a la que se suma un efecto aleatorio.

Así es como se expresa el efecto del nivel 2, sea:

$$
\beta_{0 \mathrm{j}}=\gamma_{00}+v_{0 \mathrm{j}}
$$

La ecuación final al sustituir a [2] en [1] queda:

$$
\mathrm{Y}_{\mathrm{ij}}=\gamma_{00}+\beta_{\mathrm{j}} \mathrm{X}_{\mathrm{ij}}+\varepsilon_{\mathrm{j}}+v_{0 \mathrm{j}}
$$

Un modelo que combina efectos fijos y dos términos aleatorios cuya varianza mide la dispersión entre los individuos así como entre los grupos.

$$
\operatorname{Var}\left(\mathrm{Y}_{\mathrm{ij}}\right)=\operatorname{Var}\left(v_{0 \mathrm{j}}+\varepsilon_{\mathrm{j}}\right)=\tau_{00}+\sigma^{2}
$$

La correlación entre los individuos del grupo se mide con la relación:

$$
\rho=\tau_{00} /\left(\tau_{00}+\sigma^{2}\right)
$$

Una formulación más sofisticada del modelo jerárquico siempre supone que el factor constante varía de un grupo a otro, aunque esta variación se pueda expresar en función de ciertas variables del grupo, del hogar por ejemplo o de la región.

En este caso, el factor constante se expresaría así:

$$
\beta_{0 \mathrm{j}}=\gamma_{00}+\gamma_{\mathrm{ij}} \mathrm{W}_{\mathrm{j}}+v_{0 \mathrm{j}}
$$

No cambia el número de efectos aleatorios pero se suman tantos efectos fijos como variables existan en este nivel.

El modelo propuesto para la migración internacional difiere de esta presentación en dos puntos. En primer lugar estamos en presen- 
cia de tres niveles de observación y no de dos, puesto que un agrupamiento intermedio, la familia, se interpone delante de las regiones. Luego, la variable que hay que explicar es binaria y su distribución es binomial, lo que implica el uso de un modelo lineal generalizado y de una relación logito. Dos programas informáticos ajustan los parámetros de estos modelos no lineales, pero el tamaño impuesto por la muestra (180 mil observaciones aproximadamente) nos ha llevado a descartar ${ }^{28}$ el procedimiento Glimmix escrito por Brown y Wolfinger que se basa en el procedimiento Mixed de SAS. El programa Mln ${ }^{29}$ -exclusivamente dedicado al análisis multinivel- ha resultado más eficiente aunque más difícil de aplicar al presente archivo de datos, ${ }^{30}$ de modo que algunas opciones estadísticamente más precisas se han tenido que descartar por ser inestables en el nivel informático. ${ }^{31}$

Una etapa decisiva del diseño de los modelos jerárquicos consiste en distinguir los efectos fijos de los aleatorios, normalmente en función de las condiciones de la observación y de las hipótesis postuladas. Como regla general, un efecto es fijo cuando los niveles incluidos en el estudio representan todos los niveles posibles del factor; es aleatorio cuando representan una muestra de un conjunto mayor de niveles (Litell et al., 1996). De tal manera que los factores regionales (nivel 3) se miden para todas las regiones de México, y en el caso presente nos conformaremos con estimar los parámetros exclusivamente para este territorio y no para un conjunto más amplio del cual sólo representarían una muestra. Sin embargo, algunas hipótesis más elaboradas -como por ejemplo el suponer que el o los coeficientes del modelo lineal puedan cambiar de una región a otra- nos llevarán a introducir nuevos efectos aleatorios, como los que provienen de las características familiares. Debido tanto al aspecto exploratorio de este estudio que dispone de escasas estadísticas, como a la ausencia de

\footnotetext{
${ }^{28} \mathbf{E l}$ tratamiento de una relación logito con tres niveles de una muestra como la nuestra nos hubiera tomado varios días, y además la convergencia no se hubiera asegurado: una lentitud disuasiva. Londres.

${ }^{29}$ Multilevel Models Praject, Mathematical Sciences Institut of Education,

${ }^{30}$ Del mismo modo algunas operaciones y numerosas opciones no se han podido llevar a cabo debido al tamaño del archivo de datos, ya que Mln realiza los procesos en memoria viva (memoria RAM).

${ }^{31}$ Algunos procedimientos -estimaciones MQL (Marginal Quasi Likelihood) o PQL 'Predictive Quasi Likelihood) de segundo orden - concebidos para producir estimatores más precisos (especialmente en el caso que tratamos, con una distribución binonial y pocos individuos por hogar), implicaban algoritmos más exigentes pero que en tl caso de los datos analizados no condujeron a la convergencia de las iteraciones.
} 
teoría relativa a las influencias contextuales sobre el fenómeno observado, ${ }^{32} \mathrm{y}$ a las disuasivas limitaciones informáticas, hemos diseñado un modelo:jerárquico sencillo con variaciones aleatorias en torno a las medias individuales, familiares y regionales. Se toma en cuenta la yuxtaposición de los datos descartando la hipótesis de la independencia de las observaciones. Empezaremos con un modelo indeterminado que establece variaciones en torno a la media de cada nivel, y que nos servirá de punto de referencia, aunque no pretenda explicar esta variación. A continuación se introducen los efectos en el nivel individual, luego familiar y al final regional. El cuadro 3 detalla los componentes de la varianza de acuerdo con las diversas situaciones analizadas: desde el modelo incondicional hasta la completa integración de las variables, y según se ajuste ${ }^{33}$ o no la varianza residual en el nivel individual.

Las variaciones significativas del efecto aleatorio registradas en cada nivel se descomponen entre las familias y las regiones, las cuales muestran una mayor variabilidad. Al introducir las características individuales, el componente regional de la varianza permanece sin cambios. En cuanto a las características familiares -como el efecto de las "redes migratorias" -, las mismas reducen esta variación en una cuarta parte. En total la varianza regional disminuye aproximadamente en $60 \%$ debido a la dimensión del medio ambiente registrada en el nivel de unidades regionales. Sin embargo, las ganancias resultan menos considerables al tomar en cuenta el contexto familiar, ya que la variante del efecto aleatorio en este nivel presenta cambios inesperados: disminuye a la mitad con la integración de las características del hogar, pero aumenta notablemente cuando se toma en cuenta el contexto regional, estando ambas yuxtapuestas. El análisis contextual carece visiblemente de referencias teóricas así como de un abanico satisfactorio de mediciones. Convendría introducir estructuras más complejas de la varianza (efectos cruzados entre hogares y regiones), pero los programas de cómputo de los que disponemos no nos lo ha permitido.

32 Sería necesario plantear algunas hipótesis acerca del sentido y la causalidad de las influencias contextuales: ¿̇endrán un efecto directo en la decisión de una migración o se ejercerá por medio de determinantes familiares? La hipótesis de los coeficientes aleatorios se aplica cuando suponemos que el medio ambiente influye no tanto en el fenómeno que intentamos "explicar" sino en su relación con variables independientes.

${ }^{33}$ Restringida o no a su valor esperado (la unidad) de acuerdo con la distribución binomial. 


\section{CUADRO 3}

Los componentes de la varianza en función de los distintos niveles de reagrupamiento

\begin{tabular}{|c|c|c|c|c|c|}
\hline & \multirow[b]{2}{*}{ Nivel } & \multicolumn{2}{|c|}{$\begin{array}{c}\text { Varianza ajustada } \\
\text { (de una distribución } \\
\text { binomial) }\end{array}$} & \multicolumn{2}{|c|}{ Varianza no ajustada } \\
\hline & & Estimación & $\begin{array}{l}\text { Desviación } \\
\text { estándar }\end{array}$ & Estimación & $\begin{array}{c}\text { Desuiación } \\
\text { estándar }\end{array}$ \\
\hline \multirow{3}{*}{$\begin{array}{l}\text { Modelo } \\
\text { incondicional }\end{array}$} & Regional & 0.857 & 0.095 & 0.789 & 0.089 \\
\hline & Familiar & 0.319 & 0.023 & 0.708 & 0.031 \\
\hline & Individual & 1.000 & 0.000 & 0.763 & 0.003 \\
\hline \multirow{3}{*}{$\begin{array}{l}\text { Introducción de } \\
\text { las variables } \\
\text { individuales }\end{array}$} & Regional & 0.883 & 0.099 & 0.841 & 0.095 \\
\hline & Familiar & 0.441 & 0.029 & 0.733 & 0.035 \\
\hline & Individual & 1.000 & 0.000 & 0.826 & 0.003 \\
\hline \multirow{3}{*}{$\begin{array}{l}\text { Introducción de } \\
\text { las variables } \\
\text { familiares }\end{array}$} & Regional & 0.639 & 0.074 & 0.639 & 0.070 \\
\hline & Familiar & 0.220 & 0.024 & 0.363 & 0.027 \\
\hline & Individual & 1.000 & 0.000 & 0.868 & 0.003 \\
\hline \multirow{3}{*}{$\begin{array}{l}\text { Introducción de } \\
\text { las variables } \\
\text { regionales }\end{array}$} & Regional & 0.274 & 0.038 & 0.277 & 0.039 \\
\hline & Familiar & 0.352 & 0.031 & 0.484 & 0.035 \\
\hline & Individual & 1.000 & 0.000 & 0.921 & 0.003 \\
\hline
\end{tabular}

Sería conveniente aclarar previamente las incertidumbres asociadas a la dispersión extrabinomial de la varianza residual que aparece cuando se elimina la restricción de su conformidad a la distribución (véase el cuadro 3), la cual representa una cuarta parte de la varianza esperada en el modelo incondicional. Es de notar que esta diferencia disminuye sensiblemente a la hora de introducir los factores individuales, lo que parece indicar que la dispersión extrabinomial se debe precisamente a que no se hayan tomado en cuenta las características individuales decisivas. Las que hemos conservado (el sexo, la edad y la condición de parentesco en el hogar) resultaban a priori insuficientes para abordar la migración internacional. Las razones 
aducidas por los estadísticos para explicar esta situación, que desgraciadamente es muy común, son demasiado numerosas como para sacar alguna conclusión al respecto; sin embargo los estudios de Wright (1997) ponen en tela de juicio una causa que parece decisiva en el caso presente: el número muy reducido de observaciones por grupos, en este caso los miembros del hogar. La gran cantidad de hogares que cuentan con uno o pocos miembros sería la causa de esta dispersión extra que dificulta el análisis de la contribución familiar a la migración; lo anterior se ve confirmado por la distribución de los residuos, la cual se aleja de una normal. Cabe señalar que al eliminar la restricción sobre la varianza residual, cambia de manera notable la repartición de la varianza en el sentido de una mayor variabilidad en el ámbito de los hogares.

El cálculo de la estimación de los nuevos parámetros del modelo jerárquico se realizó con la restricción de que la varianza residual se ajustara a la ley binomial. ${ }^{34}$ En el cuadro 4 vemos que no son muy distintos de los que habíamos obtenido anteriormente con el modelo logístico que no tomaba en cuenta la estructura jerárquica. Esta conclusión, que puede parecer decepcionante, era previsible. En su formulación sencilla, sin estructuras complejas de la varianza (por ejemplo de los coeficientes que varían de una región a otra), el modelo jerárquico sólo se distingue por tomar en cuenta la yuxtaposición de la información, al integrar en sus estimaciones la mayor similitud de los individuos dentro de las familias y de las regiones. Notamos de inmediato que aumenta el margen de incertidumbre asociado a las variables de los niveles superiores y, por consiguiente, la significación estadística de algunos efectos. Debido al gran número de hogares, antes que nada son las variables regionales las que muestran un incremento importante en su imprecisión estadística, lo que tiene como resultado el añadir dos efectos no significativos a los dos anteriores: el clima templado se suma al efecto de la aridez y la remuneración media de los empleados de los establecimientos se aproxima a las remuneraciones medias del conjunto de la población.

${ }^{34}$ Lo que se justifica por la muy buena concordancia final de la varianza no restringida ( 0.92 está razonablemente cerca de la unidad) y por las causas probables de esta dispersión extrabinomial. Cabe hacer notar que los programas de cómputo empleados corrigen automáticamente las consecuencias de la diferencia en la evaluación de las desviaciones estándares y de los parámetros. 
CUADRO 4

Estimación de los parámetros del modelo jerárquico

\begin{tabular}{|c|c|c|}
\hline Efecto & $\begin{array}{l}\text { Estimación de } \\
\text { los coeficientes }\end{array}$ & $\begin{array}{l}\text { Desviación } \\
\text { estándar }\end{array}$ \\
\hline Intersección & -6.302 & 0.449 \\
\hline \multicolumn{3}{|l|}{ Efectos individuales: } \\
\hline Sexo masculino & $1.750 *$ & 0.056 \\
\hline Edades (años) & $0.007 *$ & 0.001 \\
\hline Jefe del hogar & $1.287 *$ & 0.077 \\
\hline Cónyuge & $0.466 *$ & 0.093 \\
\hline Hijos o ascendientes & $-0.519 *$ & 0.081 \\
\hline \multicolumn{3}{|l|}{ Otros parientes } \\
\hline \multicolumn{3}{|l|}{ Efectos familiares: } \\
\hline Presencia de un miembro del hogar en EUA & $2.394 *$ & 0.035 \\
\hline Paridez media del hogar & $-0.070^{*}$ & 0.006 \\
\hline \multicolumn{3}{|l|}{ Efectos regionales: } \\
\hline Distancia a la frontera $(100 \mathrm{~km})$ & $-0.116^{*}$ & 0.022 \\
\hline Tierras áridas (menos de $300 \mathrm{~mm}$ de lluvias) & -0.105 & 0.248 \\
\hline Clima templado $(300-800 \mathrm{~mm})$ & -0.025 & 0.137 \\
\hline Zona rural (localidad de menos de 20000 hab.) & $0.177 *$ & 0.040 \\
\hline $\begin{array}{l}\text { Ingresos medios de la región (número de } \\
\text { salarios mínimos) }\end{array}$ & -0.051 & 0.106 \\
\hline Índice de masculinidad de la PEA desempleada & $0.007^{*}$ & 0.001 \\
\hline $\begin{array}{l}\text { Índice de masculinidad en los analfabetos de } \\
\text { más de } 65 \text { años }\end{array}$ & $0.014 *$ & 0.003 \\
\hline Proporción de uniones libres & $-0.025^{*}$ & 0.010 \\
\hline $\begin{array}{l}\text { Remuneración de los empleados en los } \\
\text { establecimientos registrados }\end{array}$ & -0.039 & 0.026 \\
\hline Zonas indígenas & $-0.671 *$ & 0.129 \\
\hline
\end{tabular}

* Los efectos son significativos a partir de 5 por ciento.

Estas ganancias pueden parecer decepcionantes en relación con el esfuerzo que han requerido pero era imprescindible realizarlo con el fin de evitar conclusiones erróneas. Con todo, hay que ser aún más prudente cuando el número de agrupamientos es reducido. Con tan sólo 198 regiones, podríamos haber sido inducidos a conservar efectos contextuales inoperantes. Este análisis no agota las potencialidades del enfoque multinivel; convendría concebir y examinar efectos combinados (por ejemplo, ser a la vez mujer y jefe de hogar, así como distinguir el efecto de las parideces elevadas en los hombres y 
en las mujeres). Una vía de investigación promisoria consistiría en atribuir a cada región un modelo de regresión propio, con una constante y una pendiente distintas (Bryk y Raudenbush, 1992). De acuerdo con esta problemática, las variables contextuales ya no intervienen solamente en la experiencia migratoria media del grupo, sino también en las relaciones entre la probabilidad de una migración y los factores personales o familiares. La aproximación gana cierta precisión analítica pero exige nuevas bases teóricas para poder formular hipótesis pertinentes. En efecto, en caso de datos muy abundantes se vuelve más complejo el manejo de las herramientas estadísticas e informáticas necesarias para su tratamiento, de tal suerte que es recomendable emprender este análisis con conocimiento de causa.

\section{Conclusión}

Hasta hace poco, se desconocía la distribución geográfica detallada de la emigración mexicana hacia Estados Unidos; ahora las investigaciones recientes nos permiten observarla, mas no nos ofrecen todavía los medios confiables para explicarla. La cartografía pone en evidencia tanto una emergente movilidad de proximidad en el norte como una fuerte concentración regional de las emigraciones que se multiplican en algunos lugares de fuerte tradición migratoria. Los mapas reflejan también que las zonas orientales húmedas del país no están sujetas a este éxodo. Nos percatamos de que la migración internacional tiene tanto una historia (la distribución exponencial de las proporciones es un argumento en este sentido) como una geografía (la distancia, el clima...), pero los determinantes propiamente regionales no aparecen con claridad.

Esto se debe en parte a que son escasas las similitudes cartográficas que nos podrían proporcionar elementos para comprender la configuración particular de la migración internacional, la cual resulta muy distinta de la migración interna o municipal. El resultado más seguro, pero también el menos previsible, es la poca incidencia de las economías regionales. La ventaja de los salarios estadunidenses parece aplastante: en efecto, las remuneraciones medias y los ingresos locales no influyen ni en el número de salidas ni en el de retornos. La distancia a Estados Unidos se confunde con la aridez, la cual seguramente ha creado un contexto favorable para la migración de los temporeros mexicanos hacia la agricultura estadunidense. Diversos 
aspectos del entorno físico o natural, examinados mediante un Sistema de Información Geográfica, resultan poco significativos al momento de controlar otras variables contextuales o características individuales y familiares disponibles. Llaman la atención algunas coincidencias de connotación más cultural, pero son delicadas de interpretar ya que hace falta poder discernir las distintas causas. Así, es posible, por ejemplo, que la escasa emigración registrada en los lugares de población indígena (en comparación con las regiones en donde está más implantada la fe católica) se deba a una coincidencia histórica regional, o bien a una predisposición cultural individual. Además es notable que este efecto disminuye con la introducción de otras características familiares o regionales, particularmente las diferencias que existen entre los sexos con respecto a la educación o a la práctica de la unión libre. En cambio, los efectos de la emigración en la estructura por edad sí son perceptibles, así como en la nupcialidad. El impacto de las anteriores fecundidades es a la vez lógico y confirmado por las cifras, pero ¿no será éste el producto de las solidaridades que existen en el seno de la familia? Resulta más clara la incidencia de la migración internacional en las desigualdades masculinas y femeninas relativas al empleo.

En fin, estamos en presencia de resultados un tanto paradójicos. Algunos determinismos anunciados por la teoría parecen incapaces de explicar la distribución geográfica de la migración internacional, pero a su vez esta última revela otras influencias más inesperadas. Asimismo, la observación cartográfica de los residuos - de la parte no "explicada" - del modelo propuesto aporta elementos interesantes en lo que concierne a la singularidad de la frontera norte y a la influencia disuasiva que tienen algunas ciudades medianas sobre su entorno rural. Pero conviene ser prudente cuando estas medidas contextuales son de características individuales agregadas, ya que en este caso no comprueban gran cosa con respecto a los determinantes regionales debido a correlaciones ecológicas. Algunas cuestiones, especialmente las que conciernen a la influencia del medio ambiente, no cuentan con un cuerpo teórico suficiente como para guiar el análisis, el cual se ve obligado a limitarse a un examen exploratorio. Es lo que hemos hecho basándonos en observaciones comunes (el ritmo estacional del trabajo agrícola migratorio, la distancia...) pero hay que admitir que hace falta un mayor esfuerzo conceptual para poder discernir entre todo este tejido de influencias, cuáles resultan ser las verdaderas influencias contextuales. 
Estas prudentes conclusiones - que reconocen las dificultades encontradas- han inspirado la segunda parte del estudio, el cual procura librar algunos de estos obstáculos mediante la introducción de modelos:jerárquicos cuya representación metodológica se encuentra en el anexo. Su asociación con los Sistemas de Información Geográfica permite:

-Tratar correctamente una información:jerárquica que presenta distintos niveles de observación y por lo tanto de agregación (individual, familiar y regional); por ejemplo, el no tomar en cuenta la escasez de la mediciones regionales nos llevaría a cometer errores en cuanto a su precisión y por lo tanto nos arriesgaríamos a atribuirles efectos inoperantes.

-Descomponer las variaciones observadas de la emigración internacional de acuerdo con los niveles de observación, y esto con el fin de determinar, por ejemplo, en qué medida las diferencias regionales de la emigración corresponden a la distribución espacial de los individuos o de las familias, para discernir de este modo la incidencia de su propia influencia.

-Intentar "explicar" cada parte de la varianza así descompuesta en función de variables observadas en cada uno de los niveles, lo que confiere una mayor precisión al análisis de las influencias contextuales.

-Examinar hipótesis más precisas acerca de la naturaleza de las relaciones entre los determinantes de cada contexto, suponiendo por ejemplo que el medio ambiente no ejerce una influencia directa en el fenómeno, sino en el juego de sus determinantes en otro nivel, como podría ser el familiar.

Si bien la teoría considera que la decisión individual de emigrar está sujeta a la influencia de diversos contextos, ya sean familiares, comunitarios o étnicos, omite tomar en cuenta sus interacciones. El uso de modelos jerárquicos o multiniveles permite plantear y verificar estas interacciones sobre bases cuantitativas. Las que acabamos de explorar siguen siendo elementales, limitadas tanto por los vacíos de reflexión en la materia, como por la escasez de las estadísticas. Se ha demostrado la importancia de la dimensión familiar al tomar en cuenta el parentesco dentro del hogar, la presencia de un miembro del hogar en el extranjero, y la paridez de la media de las mujeres de la unidad doméstica. Pero hemos de confesar que, con todo y los abundantes datos proporcionados por los Sistemas de Información Geográfica, no nos ha sido posible explicar mucha de la variación regional de la emigración internacional. Sin embargo, es necesario 
tener serias reservas al momento de la interpretación debido a que los datos provenientes de la Enadid no permiten distinguir entre la probabilidad de una salida y la de un retorno.

Queda mucho por hacer, ya que la aproximación multinivel todavía no cuenta con una base sólida; nos faltan los datos estadísticos necesarios así como programas de cómputo suficientemente eficaces como para tratar una información densa acerca del medio ambiente, a pesar de los adelantos de estos últimos años. Habría que desarrollar antes que nada un corpus de nuevas hipótesis en torno al análisis contextual de las dinámicas demográficas y en particular de la migración internacional. Resultaría sumamente interesante explorar la interacción de fenómenos registrados en distintas escalas: ¿no tendrá la desertización más impacto en la comunidad que en la propia decisión del emigrante?, y en cuanto a las diferencias culturales entre los sexos cno influirán más bien en las actitudes familiares ante la emigración?... Existe en la materia una gran variedad de nuevas interrogantes que el análisis multinivel examina en términos estadísticos más rigurosos.

\section{Anexo metodológico}

\section{La estructura jerárquica de la información localizada}

Existen varios métodos para diseñar un modelo empírico que explore las correspondencias estadísticas entre una decisión individual, como por ejemplo la de emigrar, e informaciones contextuales, en nuestro caso regionales. Se distinguen antes que nada por tomar o no en cuenta la estructura jerárquica de la información, o aún más por la yuxtaposición de diversos niveles de observación y de análisis.

El método elemental consiste en utilizar los valores agregados registrados en un solo nivel, el más alto -en este caso, el regional-, tanto de la migración como del medio ambiente. Las estadísticas requeridas provienen de los censos por una parte, y por otra del SIGEF (véase la nota 1) para documentar las características físicas y espaciales que se han de integrar al análisis. Para cada región nos conformamos con una selección de mediciones globales de la emigración internacional, que intentamos explicar basándonos en las características de la unidad espacial. No se trata de un análisis contextual propiamente dicho ya que nos quedamos sólo en un nivel regional, buscan- 
do una similitud cartográfica entre la emigración internacional y un conjunto de características del medio ambiente, algunas de naturaleza socioeconómica. De las características individuales sólo se toma en cuenta el promedio regional. Este método impone dos inconvenientes mayores al análisis. El primero implica una gran pérdida de información dado que se pierde toda la variación individual dentro de la región; ésta suele representar más de $95 \%$ de la variación total del fenómeno. ${ }^{35}$ La segunda limitación consiste en no poder obtener conclusiones acerca de las unidades elementales, en este caso los individuos o los hogares que toman la decisión de migrar. De hecho, las correspondencias (y los parámetros de la ecuación) cambiarán de acuerdo con el recorte utilizado para su reagrupamiento por regiones, un sesgo que se conoce desde Robinson como ecológico. No obstante, si bien la distribución geográfica de la emigración no corresponde a la de los factores de expulsión esperados, es poco probable que éstos actúen en el nivel individual. Esta aproximación será explorada con un buen detalle estadístico, ya que aporta conclusiones interesantes, sobre todo en torno a la influencia aparentemente divergente que ejerce el contexto regional sobre la migración nacional o internacional.

El método más riguroso, pero que exige estadísticas más detalladas, ${ }^{36}$ separa los dos o tres niveles implicados en el proceso migratorio. En el modelo se evalúa la decisión de emigrar del individuo (nivel 1) en función de criterios personales (situación familiar o profesional, ingresos esperados...), los cuales pueden verse influidos por la situación regional (salario medio, mercado de trabajo, crecimiento económico...) que constituye el nivel 2 de la información. Según la problemática analizada, se pueden introducir influencias directas que sólo afectarán la intensidad media de la migración de la región, aunque también se puedan observar posibles efectos indirectos en variables relativas al medio ambiente, los cuales modificarían la distribución y la relación entre los factores medidos en el nivel individual. Resulta desde luego más riguroso asociar distintos niveles en un mismo análisis, tanto desde un punto de vista estadístico ya que se toma

35 En el caso de la Enadid (INEGI, 1992) pasamos de más de 180 mil observaciones individuales a menos de 200 regionales.

36 Existen intentos estadísticos para evitar el efecto de agregación cuando los microdatos no están disponibles, pero sus resultados son difíciles de validar (Holt $e t$ al., 1996). 
en cuenta la no independencia de las observaciones (se repiten las mediciones regionales para cada individuo), como en el nivel ana lítico ya que la migración es por esencia una decisión individual o familiar. Sin embargo, la puesta en práctica de este análisis es más exigente dado que es preciso disponer de microdatos de la encuesta o del censo, junto con un amplio abanico de informaciones contextuales provenientes de distintas fuentes y que suelen utilizar diversas unidades de observación. Formular un modelo individual resultará probablemente más complejo, sobre todo si sólo se dispone de observaciones transversales. Por ejemplo, la Enadid (INEGI, 1992) nos da a conocer algunas características de los migrantes y de los demás, pero solamente en el momento de la encuesta. Ahora bien, algunos rasgos han cambiado desde la migración y en todos los casos ignoramos si el acontecimiento decisivo (una boda, la obtención de un empleo) ocurrió antes o después de la decisión de migrar. Sólo las encuestas biográficas que registran el calendario de los cambios de estado podrían aportar la documentación suficiente para el modelo individual. La segunda dificultad es técnica y radica en la resolución de los modelos jerárquicos cuya solución es reciente.

\section{El uso de los Sistemas de Información Geográfica}

Este estudio se caracteriza por una segunda particularidad metodológica que consiste en recurrir a los Sistemas de Información Geográfica para elaborar tanto las estadísticas del medio físico, como algunas características espaciales y, en general, una información que los censos demoeconómicos no suelen proporcionar. Nuestros conocimientos complementarios de la geografía mexicana provienen del SIGEF (véase la nota 1) el cual se compone de varios inventarios del medio físico deducidos de la cartografía temática establecida por el INEGI y la UNAM ${ }^{37} \mathrm{e}$ incluye atributos demoeconómicos correspondientes a una serie de unidades espaciales propias de cada uno de los últimos censos nacionales (1989-1992) ${ }^{38}$ Esta herramienta propone varios métodos de interrogación y análisis espacial y sobre todo la

37 Cuyas bases gráficas han sido capturadas para ser integradas en el SIGEF.

38 Desde las localidades (cerca de 90 mil), hasta los municipios, las regiones y los estados. Cada unidad va acompañada de una descripción estadística más o menos letallada. 
transferencia de la información de un nivel al otro. Por ejemplo, un indicador deducido con base en imágenes de satélite o en el inventario de suelos será inferido para cada unidad de la división administrativa. Las técnicas de la transferencia de información entre diversos inventarios, que implican el mismo número de niveles de datos, conllevan dificultades de orden estadístico.

Con el fin de no complicar excesivamente las verificaciones empíricas propuestas, procuraremos evitar la información demasiado específica, sobre todo para describir el medio físico. En efecto, estos mapas de inventario - del manto vegetal, del uso del suelo...-suelen presentar un detalle taxonómico que no tarda en imposibilitar la concordancia entre las distintas estratificaciones informativas del Sistema de Información Geográfica, lo que complicaría sobremanera su integración en el modelo migratorio. Resulta necesaria una transformación previa, basada preferiblemente en una escala numérica, al menos graduada para poder refilejar el carácter creciente del fenómeno observado. ${ }^{39} \mathrm{~A}$ modo de ejemplo, la aridez ha sido estimada en función del cálculo del déficit anual entre las precipitaciones y la evapotranspiración. Ambas mediciones son numéricas aunque hayan sido observadas mediante cortes distintos. Una interpolación previa nos ha permitido disponer de ellas para una cuadrícula idéntica del espacio. Otra estadística que también hemos examinado contabiliza el número de meses de la temporada seca, durante los cuales el balance negativo disuade las actividades agrícolas. Tratándose de las clasificaciones categóricas es recomendable una transformación previa que intente graduar el fenómeno interpretado. ${ }^{40}$ Así es como un indicador de transformación antrópica ha sido calculado con base en el inventario de las cubiertas vegetales según se encontraran éstas más o menos transformadas por el hombre. Otras medidas se deducen directamente de la localización de la información por el Sistema de Información Geográfica, como es el caso de la proximidad de los principales ejes de comunicación o la distancia a la frontera con Estados Unidos. Para aplicar esta información a las regiones que cuentan con estadísticas socioeconómicas, y sobre todo migratorias, se ha ela-

\footnotetext{
39 Esta síntesis se ha llevado a cabo con Alain Winckell, quien participa en la construcción del SIGEF, y luego se ha reincorporado a él por Michel Lepage (geógrafo físico y especialista en computación asociado al SIGEF, investigador del ORSTOM).

40 Es posible tratar una información por categorías localizada gracias a la construcción de una tabla de contingencia, pero ésta pierde entonces la referencia espacial (Wrigler, 1985).
} 
borado una sola cuadrícula fina del espacio $^{41}$ en la que se atribuye a cada unidad el valor interpolado de la característica medida: altitud, pendiente, distancia a la carretera principal, indicador de aridez, etc. A continuación se extraen los valores mínimos, máximos y promedio, así como la variación estándar de estas unidades elementales provenientes de la cuadrícula de cada una de las regiones para las cuales se han elaborado las estadísticas migratorias; es la media que se suele utilizar. Nos vemos entonces confrontados al precedente problema de la agregación de los datos y de los sesgos ecológicos cuya solución se debe buscar en el empleo de los modelos jerárquicos.

Las variables cuya contribución estadística ha sido explorada serán descritas para cada influencia esperada. $\mathrm{El}$ análisis exploratorio que hemos emprendido en primera instancia abarca un gran espectro, es decir todos los temas que cubren los censos de población realizados alrededor de 1990 (para ser más precisos el de establecimientos productivos data de 1989, y el de población y vivienda de 1990). De modo que la comparación seguirá siendo transversal, con un ligero desfase en el tiempo con respecto a la migración medida a fines de 1992 (aunque en tan sólo dos años no se ha transformado radicalmente la geografía mexicana). Una dificultad subsidiaria se debe a que las proporciones de migrantes no siguen una distribución normal; además las comparaciones lineales se complican por los límites impuestos a las proporciones (las cuales varían entre 0 y 1 ). Una transformación de tipo logito de la variable independiente $(Y)$ y el ajuste del modelo a las variaciones de (z) de tal manera que:

$$
z=\log \left(\frac{Y}{i-Y}\right)
$$

permite resolver estas dos dificultades, es decir acercarnos a una disribución normal y ajustar las estimaciones de (Y) en sus límites. Esta ransformación ha sido aplicada a las tasas de emigración, tanto inernacional como interna o municipal. Se ha introducido una pondeación para el cálculo de las correlaciones (método de los mínimos zuadrados ponderados): la de la población nativa de más de 12 años, sara moderar la mayor variabilidad de las mediciones regionales que

41 México se dividió en una cuadrícula de la cual cada elemento mide $4 \times 4$ ilómetros. 
sólo consideraban a pequeñas poblaciones, migrantes o no (pero las pruebas de validez se han realizado sin ponderación). De modo que se les ha otorgado menos peso estadístico a las regiones que varían mucho, pero que poseen fuentes de información precarias. Cabe insistir: las correlaciones calculadas entre los atributos regionales miden el grado de similitud entre las configuraciones espaciales de los fenómenos considerados, pero de ninguna manera permiten caracterizar a los migrantes con respecto a los no migrantes, y menos aún determinar los motivos de estas migraciones.

\section{Bibliografía}

Bryk, Anthony S. y Stephen W. Raudenbush (1992), Hierarchical Linear.Models: Applications and Data Analysis Methods, Newsbury Park, Sage.

Colef (El Colegio de la Frontera Norte), Conapo (Consejo Nacional de Población) y STPS (Secretaría del Trabajo y Previsión Social) (1998), Encuesta sobre Migración en la Frontera Norte de México, 1993-1994.

Courgeau, Daniel (1994), “Du groupe à l'individu: l'exemple des comportements migratoires", Population, vol. 1, pp. 7-26.

Delaunay Daniel (1995), "Mujeres migrantes: las mexicanas en Estados Unidos”, Estudios Demográficos y Urbanos, vol. 10, núm. 3, pp. 607-650.

Goldstein, Harvey (1995), Multilevel Statistical Models, Londres, Edward Arnold.

Holt, T., D. Steel y M. Tranmer (1996), "Adjustins for Aggregation Effects in Ecological Regression", en Bocquet, Courgeau, Pumain (eds.), Spatial Analysis of Biodemographic Data, John Libbey Eurotext/INED, pp. 40-62.

INEGI (1992), Censo general de población y vivienda, 1990, Aguascalientes. (1994), Encuesta Nacional de la Dinámica Demográfica, 1992, Aguascalientes.

Litell R.C., G.A. Milliken, W.W. Stroup y R.D. Wolfinger (1996), sas System for Mixed Models, SAS Institute.

Orozco Castellano, Gabriel y E. Barragán López (1955), "Maquila, trabajo femenino y género en Los Altos de Jalisco. Las trabajadoras de Capilla de Guadalupe ante la modernidad", en O. Hoffmann, T. Linck y D. Skerrit, Rancheros y sociedades rancheras, México, CEMCA, El Colegio de Michoacán/ORSTOM, pp. 273-286.

Tapinos, Georges (1993), "Can International Co-Operation Be an Alternative to the Emigration of Workers?", en OECD (ed.), The Changing Course of International Migration, Paris, Organization for Economic Cooperation, pp. 18-263.

Wright, Daniel B. (1997), "Extra-Binomial Variation in Multilevel Logistic 
Models with Sparse Structures", British Journal of Mathematical and Statistical Psychology, núm. 50, pp. 21-29, 50.

Wrigler, Neil (1985), Categorial Data Analysis for Geographers and Environmental Scientists, Nueva York, Longman. 
